\title{
Dinámica sociopolítica del conflicto y la violencia en territorio mapuche. Particularidades históricas de un nuevo ciclo en las relaciones contenciosas ${ }^{1}$
}

\author{
Nicolás Rojas Pedemonte* \\ Omar Miranda**
}

\begin{abstract}
"Del mismo modo que los mercados reales se componen de relaciones sociales creadas y cambiantes entre un número limitado de actores, otras estructuras sociales comienzan también por las interacciones entre personas. Cuando descubrimos que algunas de estas interacciones se repiten aproximadamente siguiendo la misma pauta, podemos empezar a hablar de estructura social. Más que de orientaciones individuales, se trata de lazos sociales" (Charles Tilly, 1991: 44).
\end{abstract}

\begin{abstract}
Resumen
Esta investigación revisa histórica y empíricamente el curso de la contienda política contemporánea en territorio mapuche. Desde fuentes secundarias, como también desde el mismo relato de comunidades movilizadas en la provincia de Arauco, se identifican ciertas continuidades y novedades en el actual ciclo de relaciones contenciosas entre el movimiento mapuche, el Estado chileno y el gran capital forestal. Con especial atención en el contexto sociopolítico, se estudia cómo se han transformado dinámicamente, desde un lado, las estrategias de supresión de la protesta mapuche y, desde el otro, las modalidades de la propia acción colectiva y sus fundamentos discursivos. Este estudio describe un nuevo ciclo de contienda marcado por el incremento de la conflictividad, la violencia y el cierre de los canales político-institucionales. Esta investigación plantea que las fuentes explicativas de la contienda y la violencia derivada estarían principalmente en la propia interacción entre los actores, entre sus marcos y repertorios de protesta, y el propio escenario político institucional.
\end{abstract}

Palabras clave: Contienda política - movimiento mapuche - violencia colectiva - represión - repertorios - marcos cognitivos.

\begin{abstract}
From an empirical and historical approach, this research looks at the course of contemporary contention in Mapuche territory. Drawing both upon secondary sources and first-hand testimonies of
\end{abstract}

1 Esta investigación nace de la colaboración entre el Área de Estudios Sociales SJ del Centro Fernando Vives de la Universidad Alberto Hurtado y el Observatorio Territorio y Conflicto del Proyecto Fondecyt № 1150684 del Departamento de Ciencia Política y Relaciones Internacionales de la misma casa de estudios. Se agradecen particularmente los aportes de Carlos Bresciani, de Juan Ignacio Latorre y del antropólogo Wladimir Riquelme Maulén, quienes participaron estrechamente en las reflexiones expuestas en este texto. También se agradecen los comentarios aportados por los académicos José Marimán, Esteban Valenzuela, Christian Martínez y Juan Carlos Skewes. Las reflexiones e ideas aquí expuestas son de exclusiva responsabilidad de los autores.

* Sociólogo, Universidad de Chile. Máster Europeo en Investigación en Sociología y Doctor en Sociología, Universidad de Barcelona, España. Coordinador del Área de Estudios Sociales SJ del Centro Fernando Vives, Universidad Alberto Hurtado. Coordinador académico del Observatorio del Conflicto Social, Universidad de Barcelona. Correo electrónico: nrojas@uahurtado.cl.

** Asistente de investigación, Área de Estudios Sociales SJ del Centro Fernando Vives, Universidad Alberto Hurtado. Correo electrónico: omarmic@gmail.com. 
mobilized Mapuche communities in Arauco Province, this paper reveals innovations and significant continuities within the current cycle of contentious relations among the Chilean state, the Mapuche movement and the big forest capital. Paying particular attention to the socio-political context, this study analyzes the ongoing dynamic transformation, on one hand, of the suppression of Mapuche protests, and on the other hand, of the modalities of collective action itself and its discursive foundations. This paper addresses a new cycle of contention marked by the rise of violence, unrest, and the closure of institutional and political channels. The authors argue that the explicative sources of contention and its by-product violence mainly stems from the very interaction among the actors, the frames and repertories of the protest, and the institutional political scenario itself.

Keywords: Contention - Mapuche movement - collective violence - repression - repertoires - cognitive frames.

\section{INTRODUCCIÓN}

Mientras se escribe este documento, el conflicto asociado a la causa mapuche ha transitado desde la escala local hacia una significativa notoriedad nacional e incluso internacional. Parte importante de esta notoriedad nacional responde a una caravana de camioneros forestales de La Araucanía que protestó el 27 de agosto en la capital por mayor seguridad frente a los ataques propinados aparentemente por organizaciones mapuches (El Mercurio, 24/08/2015; www. rebelion.org, 28/08/2015). Días después de recibir a los líderes camioneros, el gobierno se niega a recibir a aquellas organizaciones mapuches caracterizadas por sus propuestas institucionales y pacíficas que viajan a Santiago para expresar también sus visiones sobre el conflicto. La escena es gráfica del punto muerto en que actualmente están las relaciones políticas entre el Estado y el movimiento mapuche. Si bien la relación entre estos actores ha sido históricamente conflictiva y en las últimas décadas no ha tenido grandes vuelcos, no es ni ha sido estática. Precisamente, esta interacción histórica será abordada en el presente texto, preguntándose, finalmente, por el estado actual y la proyección de esta tensa relación.

Diversas son las fuentes que reportan una actual escalada de la conflictividad en territorio mapuche luego del último peak del año 2012 (INDH, 2014; Hernández, 2014; Pairicán, 2014). La prensa y algunos políticos de derecha han conducido durante el último año el conflicto hacia un asunto de política exterior, retomando las acusaciones del 2010 acerca de la posible colaboración entre las Fuerzas Armadas Revolucionarias de Colombia (FARC) y la Coordinadora Arauco Malleco (Qué Pasa, 30/07/2015; El Desconcierto, 08/08/2015). Mientras el gobierno de Piñera atribuía la violencia política en territorio mapuche al "terrorismo" (www.cooperativa.cl, 09/01/2012), el actual gobierno de Bachelet ha tendido a bajarle el perfil tildando de "delincuentes" a las organizaciones mapuches que se reapropian de la producción de la madera (www.mapuexpress.org, 24/01/2015; www.emol.com, 15/12/2014), cortan rutas o incendian la propiedad forestal (www.werken.cl, 30/12/2014).

Mientras los empresarios asociados al sector forestal demuestran tener una estrecha comunicación y colaboración financiera con el gobierno y la clase política (www.biobiochile.cl, 21/07/2015; www.ciperchile.cl, 23/04/2015), por su parte la resistencia mapuche se radicaliza en oposición a la gran industria de la madera (El Mostrador, 23/07/2015) y a la represión recibida. Los días previos a la caravana estuvieron marcados, por un lado, por la polémica destitución del Intendente de La Araucanía, Francisco Huenchumilla, mientras se aprestaba a 
enviar al gobierno una propuesta con soluciones políticas al conflicto (Huenchumilla, 2015). Y por otro, coincidían con el inicio de la ocupación (luego violentamente desalojada en la madrugada del 7 de septiembre) de la oficina de la Corporación Nacional de Desarrollo Indígena (CONADI) por parte de organizaciones mapuches de Malleco exigiendo la restitución territorial y la desmilitarización del territorio en conflicto.

Desde septiembre, mientras la papelera del grupo Matte ha sido legal y socialmente juzgada por su participación en una colusión de precios (El Mostrador, 12/11/2015), su empresa Forestal Mininco ha decidido temerariamente cosechar en un predio controlado productivamente hace tres años por comunidades mapuches en Puerto Choque (en el sector del lago Lleu-Lleu), desatándose desde entonces en la provincia de Arauco una escalada de violencia inusitada (Red Latina Sin Fronteras, 11/09/2015; El Mercurio, Economía y Negocios, 24/2015; www.biobiochile.cl, 11/09/2015; www.soychile.cl, 24/09/2014). La espiral de violencia (La Tercera, 11/10/2015) escaló inéditamente a zonas urbanas de Quidico (www.soychile.cl, 24/09/2015; El Mercurio, 24/09/2015) y Cañete (La Tercera, 10/10/2015), alcanzando zonas urbanas e incluso víctimas inocentes (www.biobiochile.cl, 18/11/2015).

Esta escala del conflicto propiamente forestal en Arauco se ha conjugado con los permanentes atentados incendiarios a camiones madereros (www.portalmalleco.cl, 26/09/2015) y con ciertos problemas de convivencia propios de La Araucanía (www.biobiochile.cl, 20/11/2015). En este escenario destacan cuatro hechos -más que anecdóticos- ilustrativos de la profunda ruptura de la relaciones del Estado con el movimiento mapuche ${ }^{2}$ y de su reticencia a la búsqueda de soluciones políticas: i) la compra de 12 carros blindados para el control policial del conflicto (www.biobiochile.cl, 26/11/2015); ii) la aprobación en el Parlamento de una glosa en el presupuesto del Fondo de Tierras de la CONADI que excluye del beneficio de compras a las comunidades que ocupan los predios (wWw.sofofa. cl, 27/11/2015); iii) el viaje del Ministro del Interior a La Araucanía para interponer una querella por la Ley de Seguridad Interior del Estado contra los responsables de los últimos atentados incendiarios a cuatro camiones en Lautaro (El Mercurio, 09/12/2015); y iv) la celebración de una sesión especial del Senado para abordar el problema "delincuencial" de La Araucanía, donde el Subsecretario Aleuy anunció una reunión para el 6 enero en La Araucanía donde alinearían a las policías y al poder judicial para superar el problema (La Tercera, 09/12/2015).

Este escenario del conflicto, sin duda, no responde únicamente a iniciativas individuales y espontáneas, sino más bien a una nueva fase de las relaciones entre el Estado chileno/ empresas forestales y el movimiento mapuche. No solo la intensidad de la protesta mapuche y de la violencia han aumentado desde el gobierno de Sebastián Piñera (Hernández, 2014),

2 En este estudio se hace referencia al movimiento mapuche como aquella coalición de organizaciones que, desde distintas posiciones políticas y geográficas, se reconocen parte del pueblo mapuche y luchan por objetivos comunes (la autodeterminación), solidarizando -en mayor o menor medida- entre sí y desafiando en una permanente interacción a adversarios comunes entre la élite y las autoridades en un contexto de conflicto (Tarrow, 2006). Ciertamente, el movimiento corresponde a aquellas organizaciones y actores militantes al interior del pueblo mapuche. 
sino que también la estrategia de supresión de la protesta por parte de las autoridades, en particular del actual gobierno, ha mostrado nuevas características. En este contexto la presente investigación revisará teórica y empíricamente la transformación de la relación entre las autoridades y el movimiento mapuche; en específico, cómo se han transformado, desde un lado, las estrategias de supresión de la protesta mapuche y, desde el otro, las modalidades de la propia acción colectiva.

Para entender las particularidades de este nuevo ciclo del conflicto, en particular las nuevas estrategias desplegadas por el movimiento y las autoridades, se cuenta con las valiosas herramientas analíticas aportadas por la perspectiva del "proceso político" y con su más reciente actualización, la agenda de Contentious Politics Studies. Y además se cuenta con los relatos recabados en un reciente trabajo de campo en la provincia de Arauco. Desde la teoría revisada y la información recabada directamente en terreno, este estudio pretende responder a la siguiente pregunta: ¿cuáles son las características de las relaciones actuales entre el movimiento mapuche y las autoridades, expresadas principalmente en las modalidades de protesta y en las estrategias gubernamentales para su supresión?

Este estudio describirá sociohistóricamente el curso de las relaciones entre Estado/ empresas forestales y movimiento mapuche. Respondiendo a la pregunta por las relaciones e interacciones entre los actores, se caracterizarán, históricamente y con especial énfasis en la fase contemporánea, los diversos ciclos de la contienda en territorio mapuche (con especial atención depositada en la provincia de Arauco). Diversas son las fuentes de información secundaria a las que este estudio hará referencia (indicadores sociales oficiales, registros policiales y judiciales, prensa corporativa ${ }^{3}$ y mapuche, etc.). Si bien se caracterizarán de manera cuantitativa ciertas dinámicas contenciosas de los ciclos de contienda, la mayor parte de la información será histórica y cualitativa. Durante mayo se recabó información primaria en la provincia de Arauco, donde se realizaron 34 entrevistas semiestructuradas a diversos actores. Entre estos actores destacan funcionarios municipales, funcionarios de la CONADI y de la Corporación Nacional Forestal (CONAF), empleados forestales, y principalmente miembros de comunidades mapuches en conflicto territorial. Se seleccionaron tres comunidades en disputa con una empresa forestal distinta. La primera ubicada en la zona del lago Lleu-Lleu (Tirúa Norte), en conflicto con Forestal Mininco; la segunda en Tirúa (Tirúa Sur), con una disputa territorial con Forestal Volterra; y una tercera comunidad en la comuna de Los Álamos, en disputa con Bosques Arauco. A continuación se exponen los fundamentos teóricos de la investigación y consecutivamente se van describiendo los ciclos de la contienda, con especial atención en las estrategias gubernamentales de supresión de la protesta, como también en los discursos y modalidades de protesta del movimiento mapuche.

3 Para un análisis de los sesgos del tratamiento mediático del "conflicto mapuche", véanse Labrín (2011) y Amolef (2005). 


\section{FUNDAMENTOS TEÓRICOS}

\subsection{El proceso político y la dinámica de la contienda}

La hipótesis de este estudio se sostiene en los más recientes postulados de la perspectiva del "proceso político" -Contentious Politics Studies (Tarrow y Tilly, 2007; McAdam et al., 2005; Tilly, 2003)-, que indican que el curso del conflicto social y de la violencia colectiva no responden meramente a estructuras estáticas (estructuralismo), ideas fijas (idealismo) o conductas instintivas (conductismo), sino a los dinámicos procesos históricos de la interacción de los propios actores entre sí y con sus contextos. En esta perspectiva, este estudio de la dinámica histórica del conflicto político se enfoca en las relaciones entre las autoridades y los actores involucrados; es decir, en aquellas interacciones contenciosas cargadas $-y$ generadoras- de historia que explican la violencia colectiva y la actual radicalización de la protesta en el ciclo actual del conflicto en territorio mapuche, con especial atención en la provincia de Arauco 4 .

Desde estas propuestas es posible trascender los análisis reduccionistas meramente psicológicos (Le Bon, 2004; Smelser, 1962; Gurr, 1970) u organizativos y de elección racional (Olson, 1965; McCarthy y Zald, 1977), logrando reconocer a los actores y a los movimientos en sus propios escenarios, siendo -en lenguaje propiamente tillyano- las relaciones sociales la unidad análisis. Desde el psicologicismo y el racionalismo se ha supuesto una relación directa entre las ideas y la protesta (y el conflicto), sin embargo desde esta perspectiva se transita hacia el estudio de las mediaciones propias del contexto político y relacional. Sin desestimar la relevancia de los aspectos psicosociales, organizativos y estratégicos, hoy es posible reconocer que estos resultan insuficientes cuando se estudian parceladamente y desvinculados del escenario (Neveu, 2000; Tarrow, 2011). En un conflicto con raíces históricas de larga data como el presente en territorio mapuche (Bengoa, 1985, 1999; Foerster y Montecino, 1988; Foerster, 1999; Correa y Mella, 2010; Marimán, 2012; Pairicán, 2014), también es oportuno estudiar sociológicamente su dinámica histórica contemporánea, donde hay actores concretos involucrados en relaciones dinámicas de conflicto y violencia.

Son tres las principales dimensiones que ha desarrollado -con relativa integración (McAdam et al., 1999; Tarrow, 1997)- la perspectiva clásica del "proceso político": las "oportunidades políticas", la "estructura de movilización" y los "marcos cognitivos". Ocasionalmente también se conjugaron estas tres dimensiones con el estudio de los "ciclos de protesta" y de los "repertorios de acción colectiva". En particular, este estudio prestará especial atención a la transformación de las relaciones contenciosas, destacando cómo el

4 McAdam et al. (2005: 5) entienden por contienda política "la interacción episódica, pública y colectiva entre los reivindicadores y sus objetos cuando: (a) al menos un gobierno es uno de los reivindicadores, de los objetos de las reivindicaciones o es parte de las reivindicaciones, y (b) las reivindicaciones, caso de ser satisfechas, afectarían a los intereses de al menos uno de los reivindicadores". Reconocen dos tipos de contienda, la transgresiva y la contenida. Operativamente, en su versión "contenida" se despliegan actores previamente establecidos y mediante acciones rutinarias y convencionales, mientras que en la contienda "transgresiva" al menos uno de los actores del conflicto ha sido recientemente autoidentificado y despliega acciones innovadoras. 
contexto (oportunidades políticas) y la interpretación del contexto (marcos cognitivos) por parte de los actores fundamentan determinados repertorios de acción colectiva, consolidando un nuevo ciclo con una cultura movimentista radical.

En síntesis, las oportunidades no son ni recursos ni interpretaciones o percepciones acerca del contexto, sino las propias transformaciones del sistema político que pueden traducirse en recursos y ventajas para los actores, incluso para los más "débiles" (Kriesi et al., 1998; McAdam, 1999; Neveu, 2000)5. Reconociendo su carácter estrictamente político, la propuesta interactiva de Contentious Politics Studies (Tarrow y Tilly, 2007; McAdam et al., 2005; Tilly, 2003) pone el foco en la estructura de oportunidades políticas no como una dimensión estática, sino como un contexto que cambia y es interpretado dinámicamente por los actores, mediante el mecanismo de atribución de amenaza y oportunidad. Por cierto, las transformaciones del escenario importan en función de cómo son histórica y dinámicamente interpretadas, pues si no se reconocen las oportunidades como tales es como si no existiesen.

Ciertamente, para que los actores se movilicen y se involucren en una contienda deben coincidir en la identificación de un problema o agravio y además deben compartir la percepción de que la protesta vale la pena. Los movimientos y sus militantes despliegan simbólica y discursivamente "esfuerzos estratégicos conscientes... que buscan forjar formas compartidas de considerar el mundo... que legitimen y muevan a la acción colectiva" (McAdam et al., 1999: 27). Es en la producción y reelaboración de marcos (frames) de acción colectiva (Snow y Benford, 1992; Gamson, 1992; Tarrow, 1997), en el "proceso de enmarque", donde en gran medida se juega la validez de las demandas, el compromiso con la causa y las convicciones. Este proceso surge de las propias relaciones entre los militantes en su despliegue organizativo, como también de su interacción con el sistema político y sus adversarios. De esta relación entre las oportunidades políticas y su interpretación (marcos) nacen los repertorios de "contienda política" que corresponden al conjunto de modalidades de protesta del que disponen los actores para efectuar sus demandas, y a las cuales recurren sistemáticamente, incluso cuando pudiesen existir otras posiblemente más efectivas -pero no familiares- para alcanzar sus objetivos (Tilly, 1976: 4). Los actores ciertamente cuentan con repertorios modulares, es decir, que han alcanzado amplio uso en los más diversos contextos (huelgas, barricadas, sentadas, petitorios, marchas, etc.), pero también pueden desplegar y adaptar repertorios decididamente basados en las historias de sus propias luchas locales. Para Tilly, los repertorios y las demandas que canalizan los actores pueden tener un alcance local o nacional, pueden ser particulares o modulares, como también pueden

5 Siguiendo a McAdam (1999), Tarrow (2011: 164-165) ha sintetizado con claridad aquellas oportunidades políticas de mayor consenso en la literatura: i) la ampliación del acceso a la participación para nuevos actores (derechos y apertura del sistema político), ii) desajustes en los alineamientos políticos (incertidumbre e inestabilidad electoral), iii) la división entre las élites (multiplicidad de centros de poder al interior de la élite gobernante) y iv) la disponibilidad de aliados influyentes (apoyo desde actores poderosos). Alcanzando menor consenso se sumarían a estas cuatro transformaciones políticas otros factores relevantes para la movilización como v) la conexión con alguna eventualidad internacional favorable (Ibarra et al., 2002), o aspectos menos coyunturales como vi) la capacidad del Estado para desarrollar políticas públicas (Rucht, 1999; Neveu, 2000) y vii) para ejercer la represión (Brockett, 1991; McAdam, 1999; Della Porta, 1999). 
ser más o menos directos o mediados por representantes o autoridades locales. Por su parte, en la contienda política los repertorios son acciones más o menos "innovadoras" y "disruptivas", orientadas a desafiar a autoridades, instituciones, élites u otros actores, en pos de una "causa". Por su parte, desarrollando la propuesta inicial de Tilly, Tarrow (1989) ha indicado que los repertorios de contienda suelen ser convencionales/institucionales, confrontacionales $y$, por cierto también, violentos ${ }^{6}$.

\subsection{La violencia colectiva como repertorio de contienda}

La violencia colectiva es para Tilly (2003) un repertorio instrumental para alcanzar objetivos determinados de un colectivo, cuando se estima que existe un escenario que hace necesario y propicio su despliegue. Si bien los actores movilizados y excluidos de la toma de decisiones son objeto de violencia hegemónica -como la represión policial con que son coaccionados físicamente, la violencia "estructural" con que el Estado y el modelo de desarrollo impiden su bienestar espiritual y socioeconómico, como la violencia "cultural" que naturaliza y legitima los abusos recibidos y la represión que reciben (Galtung, 1996), o como la violencia "simbólica" que impone la racionalidad y el utilitarismo occidental (Bourdieu, 2000)-, sin duda estos también son capaces de desplegar una violencia política y reivindicativa. La violencia colectiva no sería resultado de impulsos irracionales ni menos un epifenómeno de la política y de la acción colectiva, sino parte de estas y muchas veces un indicador de procesos de cambio. Es que precisamente los repertorios, y también aquellos de tipo violento, son creaciones socioculturales; no se trata de idealizaciones, sino de productos directos de la interacción entre actores concretos confrontados. Precisamente, este énfasis relacional del concepto de repertorio, que Tilly enfatizó desde la década del 90 (Tilly, 1993), se consolida en la perspectiva de Contentious Politics Studies que la presente investigación aplica.

La violencia colectiva será entendida por Tilly (2003: 25) como "una interacción social episódica que inflige daños físicos a personas u objetos ("daños" incluye la retención por la fuerza de personas u objetos, pasando por encima de cualquier restricción o resistencia); implica por lo menos a dos autores en los daños y es consecuencia, al menos en parte, de la coordinación entre las personas que realizan los actos que provocan los daños". Esta definición excluye actos meramente individuales, los daños psicológicos o morales y los accidentes, pero incluirá una amplia gama de actos que implican daños materiales o físicos (Tilly, 2003: 3-4). No se desestima una relación entre violencia psicológica y física, pero empírica y analíticamente obedecen a fenómenos distintos. La violencia colectiva es un proceso eminentemente político.

6 Para Tarrow (1989), en el repertorio "convencional" la protesta sería particularmente petitorios, audiencias, acciones legales, asambleas y en algunos casos marchas, meetings públicos y huelgas; la protesta "confrontacional" sería principalmente ocupaciones, obstrucciones, entradas forzosas y huelgas radicales; y finalmente, las protestas "violentas" corresponden a ataques a la propiedad, desafíos directos a la autoridad y enfrentamientos con la policía. 
La violencia colectiva es posible clasificarla a partir del nivel de coordinación entre los actores que la despliegan y de la proyección o relevancia de los daños originados. Determinar el grado de coordinación entre quienes despliegan la violencia política y la relevancia de los daños infligidos ayuda a "establecer y a explicar el grado de destrucción que resulta de esas interacciones ${ }^{7}$. En términos generales, la destructividad crece al aumentar la relevancia y la coordinación" (Tilly, 2007: 14). Entre las tipologías de violencia colectiva descritas por Tilly destacan por ejemplo los "ataques dispersos", correspondientes a una modalidad de violencia donde ciertos actores, en medio de una interacción de pequeña escala y no violenta, responden a las restricciones, provocaciones y amenazas por parte de actores poderosos mediante actos lesivos clandestinos y de baja intensidad sobre actores, cosas y lugares simbólicos (González Calleja, 2002: 45). Se trata de violencia de baja centralidad, pero bastante coordinada, como el sabotaje, los ataques clandestinos, asaltos a funcionarios de gobierno, incendios provocados, etc. Esta modalidad podría aproximarse, como se revisará más adelante, a los repertorios desarrollados por el movimiento mapuche en el ciclo actual.

La propuesta tillyana permite, por cierto, aproximar el estudio de la violencia hacia una perspectiva política interactiva entre autoridades y actores movilizados. Los gobiernos pueden responder de diferentes maneras a la protesta. Pueden prescribir acciones, promoviendo la lealtad y la adhesión; mientras que pueden tolerar otras que reconocen como una amenaza, o directamente prohibir aquellas que suponen un riesgo para sus recursos y objetivos. Estas respuestas, y en última instancia la relación entre autoridades y la sociedad civil movilizada, se encarnan en la noción de régimen.

Los regímenes estarían definidos por la capacidad gubernamental y la -ausencia/presencia de-democracia (Tilly, 2006: 21). Con el concepto de "capacidad gubernamental" se alude al nivel de control de los agentes gubernamentales sobre las condiciones de la población, las actividades y los recursos a lo largo del territorio administrado. Por su parte, con "democracia" se da cuenta de la medida en que los ciudadanos se relacionan con las autoridades bajo igualdad de derechos y protección, pudiendo elegirlas y teniendo influencia sobre estas. Sin duda, ningún país encarna de manera pura estos atributos (Tarrow y Tilly, 2007: 55), pero estos permiten clasificar la relación entre las autoridades y los movimientos.

En un lenguaje propio de la versión interactiva del "proceso político", es importante reparar en la asociación entre tipo de régimen y violencia colectiva (Tilly, 2003, 2006; Tarrow y Tilly, 2007; Tarrow, 2011). Se reconoce como tendencia general que las acciones

7 La "relevancia" de la violencia aumenta generalmente cuando: i) quienes participan de la contienda son especialistas de la violencia; ii) se incrementa la incertidumbre sobre los resultados de la contienda; iii) aumenta lo que está en juego; iv) se ausentan terceras partes y se aíslan los actores colectivos involucrados; y v) cuando se activan o suprimen identidades políticas, lo que impacta a todos los puntos anteriores. La "coordinación" es mayor entre los actores que recurren a la violencia cuando: i) intermediarios políticos (brokers) vinculan a actores previamente desconectados; ii) las autoridades ejercen el control de los resultados de las demandas (ya sean las recompensas o castigos); iii) las categorías identitarias que dividen y contraponen a los actores tienen presencia en la realidad social que vivencian; iv) quienes recurren a la violencia se coordinan y preparan al margen de la violencia; y v) cuando se desarrollan procesos de separación e incorporación, lo que impacta poderosamente los puntos anteriores (Tilly, 2007: 50). 
toleradas se incrementan en los regímenes democráticos y se reducen cuando aumenta la capacidad gubernamental. Así la violencia sería alta en aquellos regímenes "no democráticos de capacidad baja" ${ }^{\prime 8}$, reducida en aquellos "democráticos de capacidad alta" ${ }^{9} \mathrm{y}$, finalmente, intermedia tanto en los "no democráticos de capacidad alta"10, como también en los "democráticos de capacidad baja"11.

Aun cuando determinadas autoridades facilitan la protesta, muchas las reprimen, es decir, aumentan coactivamente su costo efectivo o potencial. La represión representa un mecanismo recurrente de "supresión de la protesta" (Tarrow, 2011: 170), entre otras alternativas menos estridentes de canalización (channeling), como la cooptación. El uso de la represión (legal o policial) se asocia a la capacidad de supresión de la protesta de los gobiernos, no obstante, se estaría en presencia de un arma de doble filo. Incluso cuando la represión puede desalentar y desmovilizar a ciertos actores, también es capaz de fortalecerlos, impulsándolos al despliegue de acciones innovadoras y radicales, entre ellas ciertas modalidades de violencia colectiva. Contrario a los preceptos clásicos del autoritarismo, Tarrow (2009: 126) sostiene que muchas veces "resulta más sencillo movilizar a gente contra una policía violenta y arbitraria que arroja a la cárcel a unos jóvenes y sinceros manifestantes que contra unas autoridades públicas razonables, que organizan seminarios para los manifestantes y protegen su derecho a la libre expresión contra sus oponentes".

Della Porta (1999: 142) ha demostrado que cuando la represión es selectiva, preventiva y legal logra ser profundamente desmovilizadora. Una represión drástica de estas características puede neutralizar a los moderados y radicalizar solo a los más militantes. En aquellas ocasiones, cuando es combinada con incentivos -e incluso con cooptación de los líderesllega a neutralizar con gran efectividad la protesta. No obstante, cuando es indiscriminada (difusa), reactiva (ex post facto), ilegal (sucia), y niega concesiones de todo tipo, aparta a los moderados del gobierno y se provoca tal sensación de indignación entre la disidencia que, en vez de fragmentarlos, acentúa sus solidaridades (Tarrow, 2011: 211). Diversos estudios

8 Regímenes no democráticos con baja capacidad: toleran muchas manifestaciones políticas, pero las pocas que prohíben y prescriben lo hacen sin gran eficacia. Ejercen un gran control cerca de su base de operaciones (especialmente en la capital), pero fuera de esa zona su control es menos vigoroso, efectivo y persistente. La contienda, cuando se desata, puede derivar en profundas confrontaciones como guerras civiles o conflictos entre diversos actores, incluyendo caudillos y criminales, amplia arbitrariedad y poder bélico. Regímenes proclives a altos niveles de violencia.

9 Regímenes democráticos con alta capacidad: en estos regímenes emerge una gran cantidad de movimientos, principalmente por el bajo riesgo y costo de la movilización. Sin embargo, las autoridades logran canalizar con eficacia política las protestas. La contienda suele canalizarse mediante movimientos sociales, grupos de interés y partidos, consultas populares y alta participación.

10 Regímenes no democráticos con alta capacidad: prohíben y prescriben muchas manifestaciones políticas, mientras toleran pocas. Por lo tanto cuando la contienda emerge lo hace violentamente. La oposición es clandestina, la confrontación es violenta y breve, y finalmente termina con una eficaz represión. Regímenes proclives a niveles intermedios de violencia.

11 Regímenes democráticos con baja capacidad: prohíben y prescriben muy pocas manifestaciones políticas, mientras toleran muchas. A igual que los regímenes democráticos de alta capacidad, promueven la movilización de actores pero sin capacidad de canalizar y monitorear la contienda, abriendo espacios para altos niveles de violencia e involucramiento de actores legales y semilegales. Suelen caracterizarse por golpes de Estado o conflictos entre diversas identidades y colectivos. Regímenes proclives a niveles intermedios de violencia. 
(Brockett, 1991; Della Porta, 1999; Tarrow, 2009; Rojas Pedemonte, 2013) han destacado modalidades contraproducentes en la represión de la protesta.

Habiendo detallado los principales elementos teóricos para el análisis de las relaciones contenciosas entre los actores, a continuación se caracterizan los ciclos contemporáneos del conflicto, con especial énfasis en el escenario actual y en la provincia de Arauco.

\section{LOS CICLOS Y LA DINÁMICA DE LA CONTIENDA}

Sidney Tarrow (2011: 134, traducción propia) ha descrito con claridad los ciclos de protesta como "una ola ${ }^{12}$ creciente y luego decreciente de acciones y reacciones colectivas interrelacionadas a aquellas cuya frecuencia agregada, intensidad y formas, aumentan y después descienden en una proximidad cronológica similar". En términos generales se puede decir que durante los ciclos de protesta: i) se intensifica el conflicto y se difunde rápidamente la movilización hacia los sectores más apartados y desmovilizados; ii) aumenta la interacción contenciosa y el flujo de información; iii) se constituyen y fragmentan identidades y coaliciones; e iv) irrumpen -o se reconfiguran- repertorios y marcos de acción colectiva (Tarrow y Tilly, 2007; Tarrow, 2009, 2010, 2011). Este último punto es de especial interés para el presente estudio, pues se presta especial atención a los discursos y modalidades de protesta en el ciclo actual.

Con todo, es posible proponer que en el estudio de la contienda política -es decir, la confrontación dinámica entre actores con intereses contrapuestos y donde al menos uno es un gobierno- los ciclos pueden ser transgresivos (movilización) o contenidos (desmovilización o lucha institucional). Para el caso de la contienda política en territorio mapuche es posible identificar -en el marco de importantes continuidades- diversos periodos asociados a ciclos transgresivos o pasivos, donde se evidencian diferencias importantes en la relación entre los actores involucrados. Este estudio describirá las transformaciones en la relación contenciosa, principalmente atendiendo, de un lado, los marcos y los repertorios de acción colectiva y, de otro, las estrategias de supresión de la protesta. Más que de ciclos de protesta, en este estudio se abordarán los ciclos de contienda, atendiendo a la transformación de las relaciones entre los actores confrontados. De tal manera, los ciclos de contienda corresponden a periodos particulares de la relación entre los actores en disputa. Estas etapas, con tendencias y dinámicas contenciosas propias, pueden coincidir históricamente -como se expresa en el Gráfico 1- tanto con las cimas de la actividad de protesta como con las cuencas de la desmovilización.

12 Respecto de los ciclos de protesta, Rucht y Bödecker (2011: 12) sostienen: "la metáfora de la ola resulta muy útil para nosotros. Después de todo, las olas pueden ser grandes o pequeñas, largas o cortas, simétricas o asimétricas. Las olas pueden ser formadas por corrientes subterráneas relativamente lentas o por terremotos y tormentas repentinas. Pueden reforzarse mutuamente o chocar unas con otras. Pueden rodar con fuerza contra rocas poderosas o desvanecerse suavemente en la arena de la playa". 


\section{GRÁFICO 1}

Ciclos de la contienda. Dinámica de la relación entre Estado/empresas

y movimiento mapuche, 1990-2014

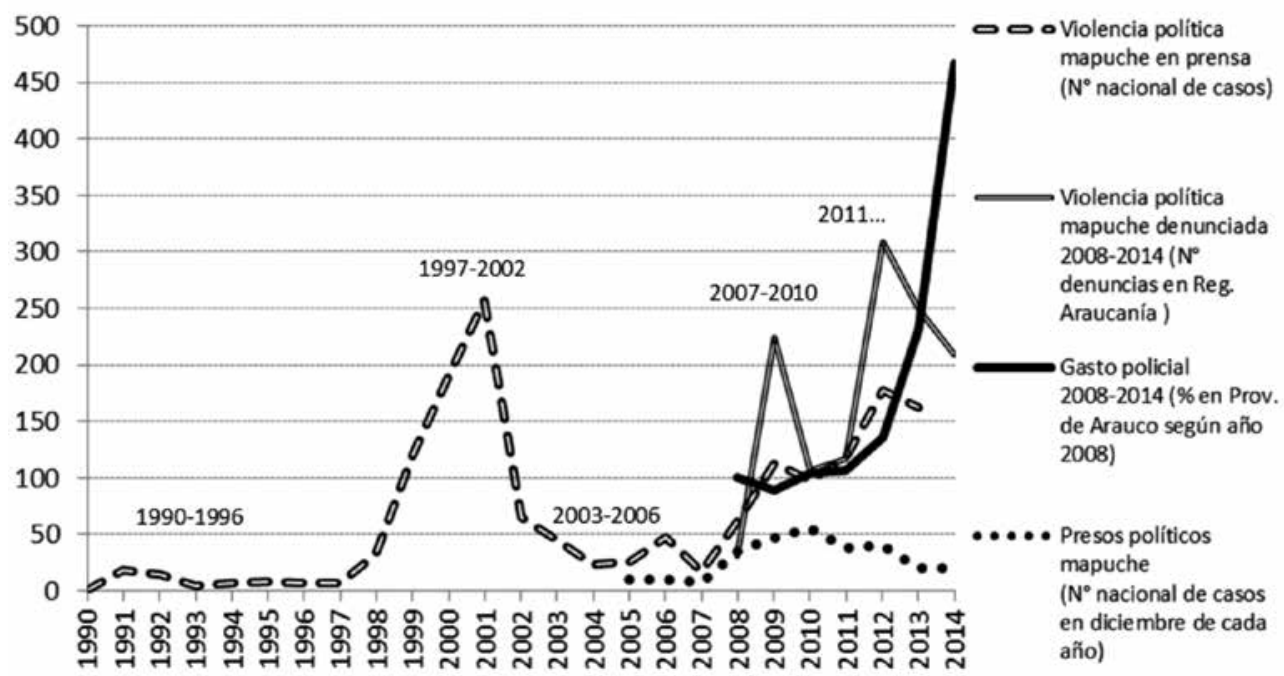

Fuente: Elaboración propia a base de i) registros de El Mercurio y Diario El Austral de Temuco ("violencia política mapuche") recopilados por Hernández (2014); ii) denuncias de "violencia política mapuche" registradas por Carabineros y fiscalías de la Región de La Araucanía, recopiladas por la Multigremial de La Araucanía (2014); iii) registros sobre gasto policial por parte de Carabineros de Chile (Subdirección e Inspectoría General, Departamento de Información Pública y Lobby); y iv) reportes de www.mapuexpress. org, www.mapuche.info, meli.mapuches.org, www.elweken.cl y de la Comisión Ética Contra la Tortura, en la sección "Represión y violencia a los movimientos sociales" de su Informe 2012 "La tortura es el miedo a las ideas de los otros".

Si bien los ciclos de contienda documentados en que ha participado el pueblo mapuche -al menos sus actores movilizados- son diversos desde la Guerra de Arauco, pasando por la Ocupación de La Araucanía hasta la política estatocéntrica del siglo XX, en las últimas dos décadas postdictadura (Gráfico 1) se reconocen continuidades, pero también ciclos con énfasis particulares en las relaciones contenciosas que los hacen distintivos (Toledo Llancaleo, 2007b; Pairicán, 2014). Esta investigación sostiene que entender las dinámicas de estas relaciones, sus énfasis y matices, brinda fundados elementos para el análisis de la contienda contemporánea en territorio mapuche. A continuación se caracterizan los cinco ciclos relacionales desde 1990 ilustrados en el Gráfico 1, pero con especial detención en el periodo reciente. 


\subsection{Revitalización de la protesta y aplicación de "la zanahoria y el garrote" (1990-1996)}

El primer ciclo, de 1990 a 1996, da cuenta de una revitalización de la protesta y de la aplicación de "la zanahoria y el garrote". Este primer periodo corresponde a un ciclo de contienda caracterizado por una intensificación de la protesta mapuche -con un marco asociado a la demanda de derechos y con repertorios clásicos de ocupación territorial- rápidamente neutralizada mediante la más clásica estrategia de supresión de la protesta, con premios o castigos para los actores según su disposición frente a la autoridad. Con una estrategia de represión selectiva y una apertura relativa de canales institucionales (con clientelismo y asistencialismo asociado), el gobierno logró desmovilizar con gran efectividad al movimiento mapuche. El gobierno de Aylwin fue capaz de neutralizar el nuevo ímpetu reivindicativo postdictadura, que alcanzó su peak entre 1991 y 1992, siendo este último el año internacional de los pueblos indígenas. La Concertación comenzaba a combinar con gran efectividad cierta apertura política -mediante una ley asistencial (Ley de Desarrollo Indígena) y la cooptación de líderes- con respuestas represivas frente a cualquier intento de ocupación territorial (como ocurrió con las tomas simbólicas del entonces nuevo Consejo de Todas las Tierras).

\subsection{La rebelión frente al extractivismo neoliberal y la criminalización de la protesta (1997-2002)}

Frente a la arremetida del gran capital y contra el modelo extractivista sustentado por los nuevos gobiernos neoliberales en sus territorios ancestrales, la protesta mapuche emergió con particular radicalidad entre 1997 y 2002, iniciando su gran escalada en el año 1999 y alcanzando su peak en 2001 (Toledo Llancaleo, 2007a; Pairicán, 2014). Casos emblemáticos de este ciclo de contienda corresponden a la resistencia al megaproyecto energético Ralco en el Alto Biobío; a la protesta frente a la industria forestal en Arauco y Malleco, iniciada en 1997 en Lumako (Tricot, 2009); y al proceso de recuperación territorial y arresto de los lonkos de Didaico y Temulemu (con la inédita aplicación de la Ley Antiterrorista). Los gobiernos, tanto de Eduardo Frei Ruiz-Tagle como de Ricardo Lagos, se mostraron capaces de prescindir de la nueva institucionalidad indígena y de asumir elevados costos políticos, en este caso la protesta mapuche, en pos del modelo extractivo desarrollista.

En el periodo 1997-1999, mientras se iniciaba la temporada de cosecha forestal, el gobierno de Frei Ruiz-Tagle incumple la Ley Indígena que resguardaba al territorio indígena, limita el Fondo de Tierras solo a Títulos de Merced y de la Reforma Agraria, prorroga el fomento forestal (Decreto Ley 701), y recrudece la represión y la criminalización de la protesta. Se iniciaba entonces una estrategia basada en la judicialización, destacando la aplicación de la Ley de Seguridad Interior del Estado.

En el segundo periodo, 2000-2002, Lagos despliega una efectiva estrategia de desmovilización, que combina una aparente apertura política -con la Comisión Verdad y Nuevo Trato que simbólicamente reconoce el agravio histórico del Estado chileno contra el pueblo mapuche y un nuevo programa de asistencia con cierto enfoque culturalista (Orígenes)- con un plan 
concertado de "inteligencia" policial (Plan Paciencia) y la aplicación inédita de la Ley Antiterrorista (Mella, 2007). El año 2001 es el peak de este gran ciclo de contienda, y da paso en los años siguientes a un marcado proceso de desmovilización. En este periodo se impulsa el aislamiento y criminalización de los sectores más radicales del movimiento, tildados judicial y mediáticamente de "terroristas", en plena sintonía con el marco de la seguridad post-11-S (Pairicán, 2014).

El 2002 comienza con el acuerdo entre Endesa y las ñañas Quintremán en Ralco, continúa con el encarcelamiento de los lonkos Norín y Pichún (bajo la Ley Antiterrorista); sigue con la entrada en operaciones del grupo paramilitar "Comando Hernán Trizano"; y con el primer mártir mapuche contemporáneo en manos de Carabineros (el menor Alex Lemún, asesinado por un Mayor de Carabineros en Ercilla). Este es un año que cambia el curso de la contienda y da pie a una significativa desmovilización de la protesta (Toledo Llancaleo, 2007a). La represión policial y legal -sobre todo después del asesinato de Lemún (Seguel, 2006) - comienza a fragmentar organizativamente al movimiento y comienza a impulsar a su facción más subversiva a la clandestinidad.

Este fue un ciclo en donde se fortaleció la capacidad disruptiva y cierto alineamiento discursivo del movimiento. Ejemplo de aquello fue el fortalecimiento y la "profesionalización" de la militancia en la figura de los nuevos weichafe (Pairicán, 2014). En cuanto a los repertorios de protesta, comienzan a ganar modularidad la ocupación territorial ya no simbólica, la denuncia internacional y los ataques incendiarios a maquinarias forestales. Sin duda, este ciclo inicia una profunda deslegitimación de los principales mecanismos institucionales de canalización de las demandas mapuches y una enérgica condena de los organismos internacionales (Stavenhagen, 2003) a la irregularidad legal con que los gobiernos reprimen la protesta.

\subsection{La clandestinidad y la promesa electoral (2003-2006)}

El periodo 2003-2006 se caracteriza por la consolidación de una férrea represión legal, la "clandestinidad activa" de la versión más radical del movimiento, y la reemergencia de la alternativa político-electoral entre las organizaciones mapuches más moderadas. En lo que la teoría conoce como el efecto de flancos radicales ${ }^{13}$, la protesta más vistosa ya no la encabezaban generalmente ñañas y lonkos con sus tradicionales indumentarias, sino principalmente jóvenes militantes con pasamontañas, mientras los líderes mapuches de cara descubierta comenzaban a apostar por la vía electoral, en ese entonces una vía no agotada.

13 Los autores definen el efecto de flancos radicales como "el incremento de las contradicciones en uno o ambos extremos de un continuo político que lleva a los actores políticos menos radicales a alianzas más próximas" (McAdam et al., 2005: 180). En términos generales, el efecto de flancos radicales hace referencia a una interacción entre facciones radicales y moderadas de un movimiento con una tercera parte. La amenaza que puede llegar a representar la facción radical para un tercer actor, como el gobierno, podría llevar a este último, por cierto, a condenar y sancionar a los moderados por su cercanía con los radicales (Haines, 1997; Gupta, 2002). Sin embargo, los estudiosos de los movimientos sociales han destacado principalmente cómo los moderados por lo general son impulsados, mediante concesiones, hacia posiciones y alianzas de centro, marginalizando así a los radicales (Gamson, 1975; McAdam, 1982; Jenkins et al., 1986; Tarrow, 2009). Por muy costosas que sean estas concesiones, las autoridades podrían estar dispuestas a asumirlas frente a las amenazas subversivas o desestabilizadoras que representarían ciertos grupos radicales. 
Luego del asesinato de Alex Lemún, la internacionalmente cuestionada persecución política de los líderes de la Coordinadora Arauco Malleco (CAM) y de todos los mapuches que desafiasen la propiedad, fue profundamente efectiva; el movimiento organizativamente se fragmentaba. Sin embargo, ganaba legitimidad discursiva y simbólica. Por su parte, la CAM continuaba, desde la clandestinidad, desarrollando un trabajo de resistencia territorial y una importante labor de enmarcamiento discursivo-ideológico, con gran énfasis comunicacional y de denuncia (de alcance nacional e internacional). Si bien la adhesión al movimiento no necesariamente decrecía, por un lado el cerco comunicacional invalidaba incluso sus iniciativas más moderadas y, por otro, las oportunidades políticas nacionales se cerraban de la mano de una coalición de gobierno estrechamente cohesionada y respaldada por el empresariado.

Ciertamente, las limitaciones constitucionales del sistema electoral chileno no brindaban espacios para la pluralidad, pero en el gobierno local parecía existir un espacio para la representación política mapuche (Marimán, 1990; Cayuqueo, 2006). Ejemplo de esta opción fueron los ocho alcaldes mapuches electos en 2004, la fundación de la organización autonomista Wallmapuwen, la ratificación del representante lafkenche en Tirúa Adolfo Millabur (electo alcalde por primera vez en 1996), y el fortalecimiento de su propia organización, Identidad Territorial Lafkenche. Sin embargo, a nivel nacional hubo frustradas experiencias en las elecciones parlamentarias -el último diputado mapuche fue Francisco Huenchumilla, democratacristiano electo en 1997- y una fallida candidatura presidencial de Aucán Huilcamán del Consejo de Todas las Tierras (CCT) en el 2005, quien no pudo oficializar su postulación por las propias limitaciones del sistema político a la pluralidad.

Lo que muchos pueden suponer como una simple desmovilización más bien fue, por un lado, una intensa actividad en la arena institucional y, por otro, un gran trabajo de enmarcamiento y legitimación de la demanda de autodeterminación por parte de los más radicales desde la clandestinidad y desde la resistencia territorial. La CAM, con 15 miembros presos y 17 en clandestinidad durante 2005, comenzaba a desplegar por esos años un marco de acción colectiva en torno a la lucha por los derechos humanos, el debido proceso y los derechos intrapenitenciarios (Pairicán, 2014: 371) ${ }^{14}$.

Este ciclo culmina con la CAM intentando recuperar posiciones en la contienda y recibiendo una nueva oleada represiva por dos eventos de destrucción de maquinaria forestal en noviembre de 2006 (el primero en Contulmo es autoadjudicado por la organización y el segundo en Cautín le es adjudicado por el gobierno), y con las frustradas tratativas de diálogo prometido por Michelle Bachelet en el segundo semestre en respuesta a la huelga de hambre en que se demandaba el debido proceso judicial.

14 La represión legal al movimiento mapuche ha sido una de las materias de mayor polémica. La vulneración del debido proceso -por ejemplo, con presencia sistemática de testigos secretos y la aplicación ad hoc de la Ley Antiterrorista contra líderes políticos mapuches- ha sido internacionalmente condenada (Stavenhagen, 2003; Anaya, 2009; Emerson, 2014), y en sí misma, motivo de protesta por parte de las organizaciones mapuches. 


\subsection{El control judicial de la "nueva guerrilla" (2007-2010)}

Entre un éxito electoral relativo (municipal), el fracaso del Nuevo Debate Nacional de los Pueblos Indígenas (la "Ley Navarro"15 no se aprueba por oposición de la Democracia Cristiana) y la nueva ola represiva a una CAM que intenta recuperar su capacidad disruptiva, surge en el 2007 una nueva organización en Malleco: Alianza Territorial Mapuche. En medio de disputas entre quienes participaban de la política winka y los radicales reprimidos judicialmente, surge esta organización que reactiva la confrontación y el proyecto de control territorial ya iniciado por la CAM. Aparece en escena una organización que grafica la modularidad que han alcanzado los repertorios radicales en el movimiento mapuche: la ocupación y el control territorial no es solo parte del repertorio de contienda de la CAM, sino también de aquellas organizaciones dispuestas a luchar en el marco del sistema político winka. Las forzosas distinciones entre mapuches "buenos y malos" o "pacíficos y violentos" (el bello trarilonko, por un lado, y la capucha, por el otro) que se habían impuesto luego del Plan Paciencia, comienzan a verse cuestionadas ${ }^{16}$. El escenario se tensiona, por un lado, con la persecución policial/judicial a la CAM y, por otro, con organizaciones dispuestas al diálogo que también comienzan a amenazar a la gran propiedad y ahora amparados ("certificados" en lenguaje de la agenda de investigación aquí utilizada) por la Declaración sobre los Derechos de los Pueblos Indígenas emitida por la ONU ese mismo año, reconociendo derechos políticos y territoriales a los pueblos originarios.

El año siguiente, Bachelet despliega una ambivalente estrategia de supresión de la protesta, brindando significativas concesiones simbólicas, mientras se transforma para muchos en el gobierno más represivo de la era de la Concertación (Donoso, 2011: 160; Pairicán, 2014: 376; Aburto Panguilef, 2009), iniciando una intensa ola represiva desde fines de 2007. La ola represiva se ilustra -en su faceta judicial- en el aumento de los presos (Gráfico 1). Mientras tanto, sintonizando discursivamente con la declaración de la ONU, el Estado chileno ratifica el Convenio 169 de la OIT y pone en marcha el Pacto Social por la Multiculturalidad, RE-CONOCER (lo que suma algunas dimensiones "participativas" y perspectiva de género al programa Orígenes). Sin embargo, aplica la Ley Antiterrorista a la CAM y a la nueva Alianza Territorial, desplegando una represión legal y policial inusitada, que se traduce en la ejecución de dos comuneros en procedimientos de desalojo (Matías Catrileo y Jaime Mendoza Collío) y en el encarcelamiento de la cúpula de la CAM.

La continuidad de la política indigenista de la Concertación se traducía en el salto desde la inteligencia policial del "Plan Paciencia" en el marco del "Nuevo Trato", a un control de la protesta que ahora descansaba principalmente en una exacerbada persecución policial y judicial de aquellas organizaciones que amenazaban la gran propiedad y en un Fondo

15 Información complementaria sobre dicha ley en: www.navarro.cl/senador-navarro-mapuches-y-ong\%E2\%80\%99spresentaron-proyecto-de-ley-contra-u[so-de-testigos-protegidos (recuperado el 20/05/2015).

16 En febrero de 2008, Pablo Castro sj, superior de la Comunidad Jesuita Mapuche de Tirúa, desarrollaba el siguiente análisis: "Mucha gente pacífica ya no cree en la palabra de los organismos del Estado. Esto es grave, se van cerrando los caminos del entendimiento y se van quebrando las confianzas. Lamentablemente el Estado ha sido tardío en sus respuestas" (Diario del Sur, 02/11/2008). 
de Tierras que aumentaba su presupuesto sin mejorar su eficiencia (según registros de la Dirección de Presupuestos [DIPRES], aumentó de \$39.613 millones en 2007 a \$79.365 millones en 2010). A diferencia del "Nuevo Trato" de Lagos y del entusiasmo electoral de mitad de década, esta ola represiva se comenzaba a desplegar en un contexto de profunda deslegitimidad de las mediaciones institucionales del conflicto. Por ese entonces, la derecha y los medios comienzan a hablar recurrentemente de una "guerrilla" bien armada y con vínculos internacionales (El Tiempo, 15/09/2008). Lo cierto es que ocupar y desarrollar un control productivo de los predios forestales, como también destruir e incendiar la propiedad de empresas forestales, se transforman en repertorios ya no exclusivos de la CAM, sino de gran transversalidad. La renuente disposición al diálogo por parte del gobierno se grafica con la siguiente imagen: tras 81 días en huelga de hambre demandando el fin de la ola represiva en el Wallmapu, Héctor Llaitul de la CAM declara el 30 de diciembre de 2007 que, frente a la intransigencia del gobierno, no queda más que ceder ante la inminencia de la muerte (Meli Wixan Mapu, 31/12/2007).

Por su parte, el gobierno de Sebastián Piñera (2010-2014) hereda un contexto caracterizado por la cúpula de la CAM encarcelada, pero con un movimiento con dos nuevos mártires, con mayores resguardos y certificación desde los organismos internacionales y con una protesta que combina estratégicamente el diálogo y la vía institucional con la confrontación. Golpeada la CAM (con gran parte de sus líderes en prisión), con influencia histórica en la provincia de Arauco, la confrontación en los primeros años de su gobierno se traslada principalmente a Malleco, con la Alianza Territorial como principal agente de resistencia junto a comunidades autónomas. El último año del primer gobierno de Bachelet y el primero de Piñera representarán entonces la faceta menos dialogante y menos dispuesta a las concesiones por parte del Estado chileno en las últimas décadas.

Piñera comienza su mandato dándole continuidad a la represión del ala más disruptiva del movimiento, sumando en 2010 nuevos prisioneros mapuches a la gran cantidad que heredó de Bachelet, alcanzando ese año el peak de la última década (Gráfico 1). Sin embargo, hay una política fundamental a la que no le da continuidad en su primer año de ejercicio: el Fondo de Tierras. Si bien el programa de compra de tierras administrado por la CONADI era criticado por la ineficiencia de sus procedimientos, representaba un catalizador del conflicto que los gobiernos de la Concertación incrementaron sostenidamente a nivel presupuestario (Gráfico 2) y ahora Piñera lo congelaba y decidía no ejecutar el presupuesto comprometido por Bachelet para aquel año. Ese mismo año, Piñera anunciaba el Plan Araucanía que destinaría US\$ 400 millones a infraestructura, desarrollo productivo, asistencia y educación, y prometía reestructurar la CONADI y reconocer constitucionalmente a los pueblos indígenas. Las medidas fueron cuestionadas por el movimiento mapuche por omitir aspectos como los derechos colectivos al territorio y el derecho a consulta consagrado en el Convenido 169 de la OIT (Metiendo Ruido, 05/06/2010).

El escenario que enfrenta el nuevo gobierno no es sencillo. Por su parte, los comuneros encarcelados despliegan huelgas de hambre históricas exigiendo un debido proceso. Mientras tanto el gobierno, frente a los nuevos márgenes normativos internacionales y a 


\section{GRÁFICO 2}

Presupuesto CONADI y Fondo de Tierras, 2007-2015 (cifras en millones)

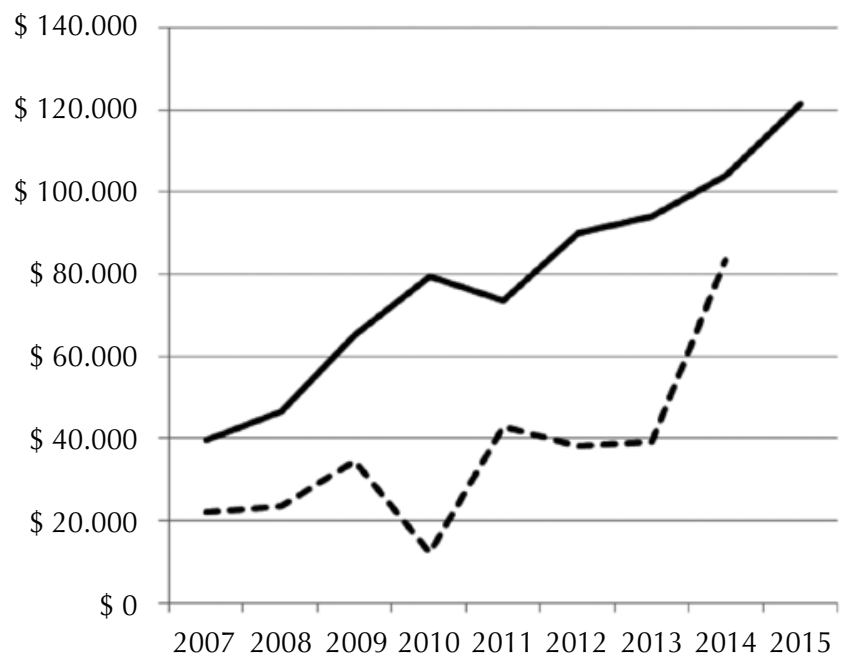

- - - Presupuesto Fondo de Tierras (ejecutado)

- Presupuesto CONADI (vigente)

Fuente: Elaboración propia en base a DIPRES.

demandas que han recibido importante certificación internacional, muestra cierta apertura al diálogo, brindando las concesiones que Bachelet negó: por ejemplo, luego de 81 días de huelga de hambre por parte de presos mapuches exigiendo un debido proceso, el gobierno compromete reformular la aplicación de la Ley Antiterrorista y establecer un mecanismo para acabar con el doble procesamiento.

Sin las redes clientelares y la penetración social con que contaba la Concertación en el pueblo mapuche, el gobierno de Piñera despliega una administración del conflicto de alto impacto mediático. Por un lado, realiza ciertos guiños discursivo/simbólicos a la normativa internacional de los Derechos Indígenas, y por otro, despliega un espectáculo bélico frente a las comunidades que inician recuperaciones territoriales de hecho en el marco del congelamiento del Fondo de Tierras. La resistencia territorial mapuche -ahora con gran protagonismo de comunidades autónomas y de la Alianza Territorial en Malleco- es persistente, y ya desde el asesinato de Catrileo el movimiento había comenzado a exhibir cierta presencia de armas de fuego (Pairicán, 2014). Mientras en la provincia de Arauco la CAM se mostraba debilitada por la represión legal/policial y se preparaba el regreso del histórico líder Adolfo Millabur a la alcaldía de Tirúa (triunfarían luego en las elecciones municipales de 2012 ocho alcaldes mapuches, cuatro de ellos identificados con el movimiento), el gobierno identificó en Malleco a su principal enemigo, la Alianza Territorial.

En respuesta al congelamiento de la compra de tierras se activan a mediados de 2010 diversos procesos de recuperación territorial en La Araucanía, especialmente en Teodoro 
Schmidt, Padre Las Casas, Cunco y Ercilla. Destacarían en esta última comuna, en el sector de Chequenko, aquellos que serían casos emblemáticos de este ciclo de contienda: la resistencia de la comunidad Wente Winkul Mapu y Temucuicui.

\subsection{El espectáculo policial, la deslegitimidad institucional y la legitimidad de los repertorios confrontacionales antiforestales $(2011-2015){ }^{17}$}

El actual ciclo de la contienda que comienza en el 2011 se puede caracterizar -a riesgo de las impresiones del análisis en tiempo real- por el espectáculo policial, el cierre y la deslegitimidad de los canales político-institucionales y la transversalidad de una cultura movimentista radical y antiforestal.

El primer año de gobierno de Piñera fue el preludio de un nuevo ciclo de contienda, con mayores niveles de conflictividad y nuevos repertorios de acción colectiva. El 2011 Piñera eleva significativamente la compra de tierras y desarrolla concesiones con el nuevo ministro Joaquín Lavín en Desarrollo Social y Jorge Retamal en la CONADI, pero serían los espectaculares allanamientos en Ercilla los que mejor representan el giro policial/militar que daba la política de supresión de la protesta en el gobierno de Piñera. El 2011 terminaba paradojalmente con la histórica entrega del fundo Santa Rosa de Colpi a los lonkos Aniceto Norín y Pascual Pichún, y con un nuevo allanamiento a la comunidad Wente Winkul, que ahora sumaba, a los diversos heridos de allanamientos anteriores, a un niño de 13 años detenido. El año siguiente, los niveles de conflictividad serían inusitados.

El año 2012 es el peak de la confrontación y de los hechos de contienda en los últimos años (Gráfico 1). Ciertamente, no existe un solo factor explicativo de aquello. El historiador Fernando Pairicán (2014) destaca, por ejemplo, la fragmentación y la emergencia de nuevos liderazgos rupturistas mientras la cúpula de la CAM se encuentra en prisión. Pero también es posible considerar otros procesos de cambio en el escenario que lo gatillan: por un lado, una espiral de oportunidades políticas en un contexto nacional de intensas movilizaciones desde 2011 (apoyo de aliados disponibles y aumento de la innovación y la incertidumbre en el escenario político), con un gobierno de derecha y presencia de potenciales "tribunos del pueblo" en la oposición (por cierto, también para un movimiento generalmente es más fácil ganar adhesión contra un gobierno represivo de derecha que frente a uno también represivo de centro izquierda que en apariencia sintoniza con la cultura y demandas del movimiento); y por otro, la entrada en agenda de la nueva Ley Forestal. Si bien el conflicto desde sus inicios ha tenido a la industria forestal como epicentro, el 2012 esto se hace explícito en plena discusión de la Ley Forestal con el aumento exponencial de los atentados incendiarios a las empresas forestales en Arauco y la intensificación del conflicto en Malleco. Este escenario encontraría un potente titular mediático en la trágica muerte de 7 brigadistas

17 Este documento terminó de escribirse durante la primera quincena de diciembre del 2015, con lo que sería posible indicar que el análisis y la descripción de este último ciclo alcanzaría a cubrir el periodo 2011-2015. Para esta sección se recurrirá a datos históricos y estadísticos, pero cuando se haga referencia a Arauco se apelará también al relato recogido recientemente en las propias comunidades. 
de Forestal Mininco el 5 de enero mientras intentaban sofocar un incendio en Carahue (López y Nitrihual, 2014).

Así también, tal como el asesinato de Matías Catrileo fortaleció la adhesión y exacerbó la vía confrontacional en el movimiento mapuche, habrá dos hechos más que marcarán un notorio giro represivo por parte del gobierno hacia un nuevo ciclo de relaciones contenciosas: el asesinato del sargento del Grupo de Operaciones Policiales Especiales (GOPE) Hugo Albornoz en abril en Ercilla y el asesinato en Vilcún del matrimonio de colonos Werner Luchsinger (75) y Vivianne Mackay (69) durante un incendio provocado en su casa en días de la conmemoración del asesinato de Matías Catrileo, ocurrido cuatro años antes en el fundo de Jorge Luchsinger, primo de Werner. Estos hechos se transformaban en el eje de la política persecutoria del gobierno, al punto de aumentar la presencia policial en la zona, incrementando los arrestos y el gasto policial en las provincias de Malleco y especialmente de Arauco desde el 2012 (Gráfico 1). La violencia y la desvalorización de la vida aumentaba las víctimas de un lado y otro, y fortalecía la identificación del otro como un adversario.

Mientras el 2012 se caracteriza por la discusión de la Ley Forestal, por la intensificación de la contienda tanto electoral (municipal) como transgresiva (con el peak de hechos de violencia), y por la persecución de los comuneros de Ercilla y particularmente de la Alianza Territorial, el 2013 comienza con la inédita detención de tres líderes espirituales mapuches (las machis Francisca Linconao de Cautín y Millaray Huichalaf de Pilmaiquén, y el machi sindicado como responsable de la muerte de los colonos en Vilcún, Celestino Córdoba), sumándose a esto la polémica y mediática detención en Lleu-Lleu de un presunto "agente externo" involucrado en la CAM, Emilio Berkoff. En este contexto, diversas organizaciones -incluso las más moderadas- canalizan internacionalmente (www.mapuche-nation.org, 30/06/2013) acusaciones contra el gobierno por "montaje" y "guerra sucia" (Movimiento Generación 80, 14/01/2014).

El 2013 se caracteriza por el mediático juicio al machi Celestino Córdoba (condenado por el caso Luchsinger-Mackay), el férreo control policial en el territorio en conflicto con una tendencia creciente del gasto policial y por los "ofertones" programáticos en plena campaña electoral durante el segundo semestre. Entre las diversas propuestas, en el programa de Bachelet para su segundo gobierno destacaban reformas institucionales como el esquivo reconocimiento constitucional, la creación de un Ministerio de Asuntos indígenas y de un Consejo Indígena, y así también se comprometía cierta defensa de las lenguas y las culturas indígenas, el fin de la aplicación de la Ley Antiterrorista y el inicio de una discusión relativa a un nuevo modelo de convivencia pluricultural y respecto de alternativas a la compra de tierras para la restitución territorial. Se comprometía el envío de un proyecto de ley en los primeros 100 días de gobierno con las reformas institucionales indicadas; reformas que, siguiendo las pautas de los gobiernos anteriores, pasaron a segundo plano y no se cumplieron, al menos hasta fines del 2015, momento en que se terminó de preparar este documento.

En este escenario, los años 2014 y el 2015 han dado cuenta de una nueva relación entre el gobierno y el movimiento. Sin iniciativas de reconocimiento de derechos colectivos al territorio ni inclusión política, el gobierno intenta resolver con cierto esfuerzo presupuestario 
el conflicto, aumentando la compra de tierras y la presencia policial. Con todo, la compra de tierras aún carece de la inyección presupuestaria demandada ${ }^{18}$, y recientemente -en un nuevo cierre de los canales políticos de las demandas mapuches- se ha excluido del beneficio a las comunidades que ejercen control territorial en los hechos (El Mercurio, 27/11/2015). Esta nueva traba en la política de compras se suma a la existencia de actores como Forestal Mininco (Grupo Matte) que se resisten a vender y dialogar, aun cuando la tendencia de las grandes forestales como Arauco (Grupo Angelini) y Volterra (capital japonés) es a negociar frente a las jugosas ofertas de compra por parte de la CONADI ${ }^{19}$.

Luego del peak de la contienda en 2012, el movimiento desde 2013 se comenzaba a mostrar disperso e inmerso en disputas internas entre facciones (Pairicán, 2014: 388); sin embargo, desde fines del 2013 aparecían nuevos énfasis y tendencias en el repertorio de contienda que daban cuenta de una radicalización de la protesta mapuche, ahora especialmente en la provincia de Arauco: aumento de los atentados incendiarios a la propiedad forestal con los enfrentamientos por el Fundo El Canelo como un hito (La Segunda, 20/11/2013; País Mapuche, 19/12/2013; www.mapuexpress.org, 05/03/2014; El Mercurio, 04/03/2014); y, luego del asesinato del comunero José Quintrequeo en octubre de 2014 en Galvarino (atropellado por un tractor [Portal Radio Universidad de Chile, 02/11/2014]), con mayor recurrencia e impacto mediático se visibilizan acciones colectivas que van más allá de la autodefensa, como el corte de rutas (incluida una "emboscada" a Carabineros con armas de fuego [La Tercera, 05/10/2014], y además se generaliza el "robo" de madera [EI Sur, 13/11/2015]). Al final de la presente sección se hará referencia a estos repertorios que, ciertamente, dan cuenta de una nueva cultura contenciosa en el movimiento mapuche y de una nueva dinámica relacional.

Este nuevo ciclo evidenciaría ciertas convergencias discursivo-interpretativas en el movimiento mapuche, según lo indagado cualitativamente en las comunidades entrevistadas en la provincia de Arauco. Más allá de las divergencias en el ideario político de las comunidades entrevistadas (grosso modo, una anhela la liberación nacional, otra la autonomía regional y otra la inclusión con derechos especiales en el Parlamento), los marcos de acción colectiva transversales identificados pueden resumirse en los siguientes: i) "la deslegitimidad institucional", propia del actual escenario político nacional (PNUD, 2015), pero principalmente basada en la experiencia acumulada de reveses en la canalización institucional de las demandas. El descrédito institucional responde al poco impacto de las experiencias de diálogo y consulta, y a la deficiente implementación de los compromisos internacionales contraídos por el Estado sobre derechos indígenas. ii) "La legitimidad de la confrontación y la violencia política", fundamentada, por un lado, en la autodefensa frente a la exacerbada represión policial pero, por otro, en la férrea cerrazón política y las

18 El ex-Intendente Francisco Huenchumilla estimó -en un programa de Televisión Nacional de Chile (El Informante, 25/08/2014) - en mil millones de dólares el presupuesto necesario para el Fondo de Tierras.

19 Llama la atención que haya sido Mininco la primera empresa en vender en el 2002 en Ercilla el Fundo Alaska en Temucuicui, Ilamando a las autoridades a controlar el "desgobierno" que los obligaba a retirar su inversión en la zona. 
nulas alternativas institucionales y de diálogo efectivo. Sin duda, el Estado no le estaría ofreciendo incentivo a la moderación. iii) "El marco antiforestal", por su parte, destaca el daño ambiental, económico y cultural de la industria forestal, pero además reconoce en las empresas concretas a un adversario, a un invasor de su territorio ancestral, a un agente de violencia en la zona. Los relatos destacan los abusos económicos, laborales y ambientales de las empresas en el territorio, pero además la mala convivencia que establecen con las comunidades, destacando aquí principalmente Forestal Mininco del Grupo Matte (la única empresa que no vende ni dialoga desde 2002). iv) Finalmente, se vislumbra un cuarto marco, "la espiritualidad mapuche y el Küme Mongen" (Buen Vivir en mapudungun). La cosmovisión mapuche, en sintonía con un "ecologismo" profundamente práctico y espiritual, le da fundamento a la tenaz lucha de las comunidades contra las empresas forestales. La revaloración de la espiritualidad mapuche -expresada, por ejemplo, en la revitalización del Nguillatún o la figuración pública de los machis- alcanza cierta dimensión política que, sin duda, nutre y fortalece las convicciones. El Küme Mongen, como modelo de vida y convivencia armónica en y con la naturaleza, es el fundamento recurrente en el discurso antiforestal de radicales y moderados en el movimiento mapuche. La supervivencia del pueblo mapuche la reconocen estrechamente ligada a la preservación de la Ñuke Mapu, y el gran capital en su faceta forestal es la principal amenaza que identifican en la provincia de Arauco. La espiritualidad mapuche y el respeto a la naturaleza son categorías de gran transversalidad y resonancia en el discurso político mapuche, incluso en las generaciones más jóvenes de militantes. Un joven líder de la comunidad entrevistada en Tirúa Sur es elocuente al respecto: "Es una lucha que hay que darla, porque para nosotros es la subsistencia la que está ahí, porque nosotros dependemos de la tierra. Sin nuestra tierra no somos nada, la tierra y todo se está deteriorando. Pero no solo es la tierra, sino que todo lo que lleva la tierra, está el subsuelo, está el agua, los árboles, los animales".

Más que una inclinación política, la defensa de "La Tierra" frente a la explotación forestal respondería a un asunto de extrema urgencia. Lo que está en juego -según relatan- es más que una ideología, se trata de la supervivencia y los costos que están dispuestos a asumir en esta lucha son elevados. Y, ciertamente, en esta causa no escatiman esfuerzos ni modalidad de lucha. En el ciclo actual no son radicales únicamente sus discursos, sino también sus repertorios de contienda. A continuación se describen ciertos repertorios radicales que han ganado modularidad y transversalidad ideológica en territorio mapuche, particularmente en la provincia de Arauco.

Los marcos cognitivos anteriormente expuestos se traducen en la modularización de repertorios que concretizan la interpretación del escenario ya descrito y que, en definitiva, caracterizan el momento actual de la contienda en Arauco. Las tres comunidades entrevistadas cuentan con idearios políticos diversos, sin embargo, todas - con mayor o menor frecuenciausan o han utilizado repertorios convencionales de contienda (institucionales), pero también confrontacionales (acciones altamente disruptivas como la ocupación, las huelgas de hambre o el corte de caminos) y violentos (desarrollando daños a personas u objetos). El siguiente Gráfico intenta caracterizar grosso modo en un plano cartesiano las posiciones políticas de las comunidades y el tipo de repertorios de contienda desplegados. 


\section{GRÁFICO 3}

Posición de las comunidades entrevistadas según modalidad de contienda (repertorio) y solución al conflicto que proponen

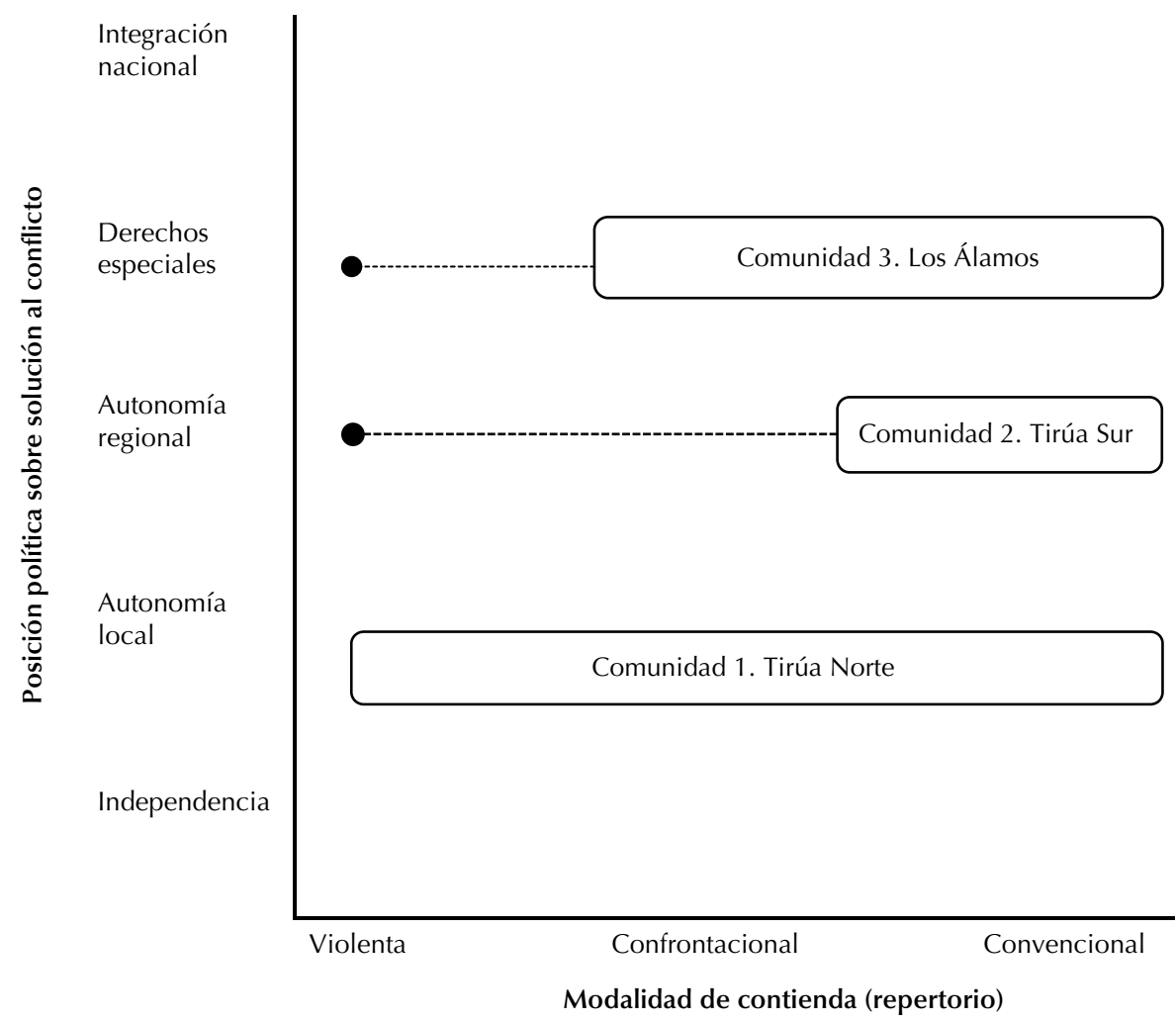

Como ilustra el Gráfico 3, las tres comunidades -independiente de sus diferencias ideológicas- han desplegado desde repertorios institucionales pacíficos hasta repertorios violentos que podrían provocar daños en personas u objetos. Ciertamente, han recurrido con distinta frecuencia a cada tipo de repertorio y no todas están dispuestas a involucrarse en enfrentamientos, pero todas coinciden -en línea con el marco de "la legitimidad de la confrontación y la violencia política" - en que "todas las formas de lucha son válidas" (adulto, presidente de comunidad de Los Álamos). Y por cierto, en línea con el "marco antiforestal", los repertorios radicales se justificarían "mientras se logre el propósito de sacar a las forestales, porque esa es una: una es la recuperación de la tierra y la otra es echar a las forestales. Porque nosotros vemos el daño que está hecho" (dirigente de la comunidad de Tirúa Sur). Ya no parece necesario apostar por la independencia y la "liberación nacional" para optar por repertorios "violentos", ya sea por la provocación de daños humanos o materiales en el adversario. 
La experiencia acumulada y la dinámica propia de la contienda parecen hoy haber radicalizado los repertorios. Desde las históricas tomas simbólicas del CTT de inicios de los 90, se ha transitado a repertorios confrontacionales y violentos complementarios $-y$ a ratos sustitutos- de los convencionales/institucionales. Si bien existe una significativa continuidad en los repertorios utilizados desde 1997 en Lumako (consolidándose las marchas, las tomas de predios y oficinas gubernamentales, las huelgas de hambre y la denuncia internacional como prácticas recurrentes), en el ciclo actual han alcanzado gran modularidad repertorios altamente disruptivos a modo de "ataques dispersos" (Tilly, 2013), destacando el incremento de los ataques incendiarios selectivos a la propiedad forestal, el "robo de madera" y los cortes de rutas.

Con gran persistencia, pero aprovechando estratégicamente las ocasiones que la industria forestal brinda, las comunidades moderadas y radicales parecen haber identificado en el "robo de madera" un repertorio con menos costos represivos que los asociados al control territorial efectivo. Si bien el control productivo del territorio es una estrategia que mantiene en vigencia la resistencia mapuche, este nuevo repertorio también daña el patrimonio económico de las empresas, pero sin duda con un costo menor para las comunidades. Resulta posible que si la dinámica principal hasta ahora en las zonas de mayor conflicto ha sido la secuencia "ocupar y controlar productivamente el territorio y luego ser reprimidos/ desalojados", ahora diversas comunidades estén optando por cosechar ambulatoriamente sin instalarse en los predios, evitándose así los costos asociados a la represión.

Este nuevo repertorio conocido como "robo de madera" no se asimila al histórico y persistente abigeato propio del mundo rural, sino se trata de una práctica particular, extendida y masificada hoy en la zona. Mientras el gobierno adjudica estas acciones a organizaciones oportunistas que lucran con el negocio de la madera (www.cooperativa.cl, 28/12/2014), las propias comunidades identifican estas prácticas como una legítima reapropiación de los recursos del territorio mapuche. En las comunidades se reconoce que son ellos mismos, al menos las comunidades entrevistadas en Tirúa Sur y Tirúa Norte, quienes protagonizan estas iniciativas. Un dirigente de la comunidad Tirúa Sur lo explica con claridad: "Pero nosotros reconocemos que nosotros somos los que sacamos la madera, porque es una forma de lucha, de hostigamiento hacia las forestales. Nosotros de alguna u otra forma tenemos que hacerle presión a las forestales para que se vayan. Pero ellos no quieren reconocer eso, dicen 'son ladrones de madera', no dicen que son las comunidades".

Tal como se expresa en esta cita, la reapropiación de los recursos forestales no responde solo a una autorreparación económica de los agravios históricos, sino también a una acción con un marcado contenido político. De tal modo, en la actualidad se estaría frente a un nuevo repertorio de contienda extendido con gran transversalidad. Si bien como práctica no es nueva, sí lo es como repertorio político. Su amplia modularidad en la zona se fundamenta directamente en el "marco antiforestal", notoriamente presente hoy en el movimiento mapuche. El objetivo no es solo aumentar la incertidumbre en la contienda y desafiar al adversario, sino concretamente expulsarlo mediante el desgaste y la merma de sus réditos.

El gobierno desestima públicamente el componente político del "robo de madera", velando así una de las principales causas estructurales del conflicto que las comunidades 
identifican: la presencia forestal en su territorio. Desde la misma comunidad de Tirúa Sur explican la reticencia del gobierno a ver la raíz forestal de la contienda: "el Estado no hace nada, hace oídos sordos a todo lo que es la problemática mapuche. Acá dicen que la gente roba, que andan ladrones de madera, pero no reconocen...".

Por su parte, los "ataques incendiarios a la propiedad forestal" se han consolidado como otro de los más representativos repertorios del actual ciclo de contienda. Tanto los ataques a maquinarias como a las plantaciones, a pesar de que no todos son reivindicados por el movimiento mapuche e incluso muchas de las "víctimas" son acusadas de ser los propios responsables materiales (Aylwin et al., 2014; López y Nitrihual, 2014; El Mostrador, 02/07/2015; El Mercurio, 02/07/2015), los estudios disponibles ${ }^{20}$ registran la alta recurrencia y consolidación de esta modalidad de protesta. Las dificultades para reconocer responsabilidades cuando se arriesgan altas penas judiciales merman la fiabilidad de los antecedentes disponibles, sin embargo los relatos recabados off the record en el trabajo de campo en la provincia de Arauco, como también el exponencial aumento de los incendios intencionales en territorio mapuche (registros de CONAF), permitirían inferir que, si bien no todos los atentados incendiarios son ocasionados por organizaciones mapuches, gran parte sí lo es y representa uno de los principales repertorios de contienda en el ciclo actual. Al respecto, una de las comuneras menos politizadas entrevistadas en Tirúa Norte grafica con claridad que las "quemas" corresponden a acciones con connotación político-reivindicativa contra las empresas forestales: "Todos los años se arman incendios... están matando todos esos árboles para que se empiecen a rescatar cosas mejores, es por eso que -no sé si los de aquí o los de afuera- vienen a quemar los bosques de los grandes empresarios. Aquí no le están quemando los bosques a cualquiera, sino a Mininco y Volterra". El objetivo, ciertamente, sería -tal como con la quema de camiones y máquinas forestales- la expulsión de las empresas madereras y el marco "antiforestal" y la "legitimidad de la violencia política" lo fundamentan. $Y$ desde estos marcos cognitivos los incendios de las plantaciones no solo son "necesarios" para la reivindicación territorial, sino además "justos". Tal como una dirigenta de la comunidad de Tirúa Norte sostiene, el daño a las forestales parece menor en comparación al que ellos generan: "si se quema algo no pierden nada... prácticamente se llevaron toda el agua".

Estos repertorios radicales contra las forestales no se justifican únicamente desde el negativo impacto económico de las forestales en la zona, sino también desde la amenaza que representan para el medio ambiente. Y precisamente la amenaza no la identifican a largo plazo, sino en los procesos actuales de sequía y en la inminencia de importantes catástrofes ecológicas. Para las comunidades de Tirúa Norte, por ejemplo, el lago Lleu-Lleu estaría bajo una gran amenaza. "Tanta invasión de árboles, obvio que la laguna se va a secar.

20 Mientras los registros de la Multigremial de La Araucanía en su Barómetro de la Violencia solo incluyen registros oficiales y una mirada parcial del conflicto (www.multigremialaraucania.cl/es_barometro_de_conflicto. php), los cinco informes sobre "Conflictividad en la Región de La Araucanía" realizados por la Fundación Chile Intercultural en 2015 (www.chileintercultural.org) recopilan valiosa información de diversas fuentes (incluida la prensa mapuche) y procuran caracterizar el conflicto como una interacción entre diversos actores involucrados. 
De aquí a 20 años nos dicen que vamos a estar sin agua", sostiene la menos politizada de la comunidad entrevistada.

Con todo, es importante atender a una nueva tendencia general en los repertorios de los sectores más subversivos. Desde la clásica autodefensa en los propios predios, las reivindicaciones violentas han transitado en el último año hacia carreteras de gran afluencia y han escalado a zonas urbanas (contraviniendo, por ejemplo, la política histórica de la CAM de mantener su accionar disruptivo en las zonas rurales). Ejemplo de esto son los incendios de camiones madereros en carreteras (principalmente en La Araucanía) y la escalada en Arauco desde las barricadas y la resistencia con municiones de fuego en las rutas (El Mostrador, 05/10/2014, 24/10/2014; El Mercurio, Economía y Negocios, 23/10/2015), hasta los ataques incendiarios -enunciados en la Introducción de este documento- en zonas urbanas de Cañete y Quidico a máquinas y propiedades vinculadas a Forestal Mininco y sus trabajadores en los meses de septiembre y octubre del $2014^{21}$.

La experiencia movimentista acumulada acerca de los límites de la vía institucional, pero además sobre el costo humano de la violencia policial en las iniciativas de control territorial parece -al menos en la información recabada en las comunidades de Araucohaber limitado las alternativas: se despliega una reapropiación ambulatoria de los recursos madereros, evitando así los costos de la represión policial, o se resiste y se ejerce de facto el control territorial productivo sobre los pertrechos de armas de fuego.

La tenencia de armas de fuego en los predios bajo control territorial y productivo disuade significativamente el ingreso de Carabineros, configurando paradójicamente una tensa paz en un territorio donde las víctimas de la represión policial comienzan a ser principalmente las comunidades desarmadas. El control territorial en los hechos, si bien es y ha sido una alternativa transversal entre moderados y radicales, aparentemente estaría tendiendo, en el contexto actual de militarización, a ser un asunto de jóvenes militantes de gran compromiso y convicción. Mientras, por su parte, los más moderados (aunque también los más radicales) optarían por repertorios con menores riesgos y costos asociados como la "reapropiación ambulatoria" de la producción maderera. Una tercera alternativa, también en la lógica de "ataques dispersos", que disminuye los costos de la represión, parece ser el factor sorpresa en los cada vez más recurrentes cortes de ruta y en los atentados incendiarios a la propiedad forestal.

En suma, se trata de repertorios que desafían profundamente la legalidad pero que actualmente estarían alcanzando gran transversalidad, ganando legitimidad -y también "ejecutantes" - incluso entre los sectores históricamente moderados y menos militantes. El escenario actual suma a los clásicos repertorios la transversal reapropiación de la madera y los recurrentes atentados incendiarios a la propiedad forestal como desafíos persistentes a un

21 Por cierto, determinados sectores del pueblo mapuche y del propio movimiento en Arauco han reaccionado con repudio a la escalada de la violencia a zonas urbanas. Sin duda, resulta importante darle seguimiento a estas voces, pues podrían eventualmente brindar señales de un incipiente descontrol de la violencia con efectos contraproducentes entre las propias comunidades (estacioninfo.blogspot.com, 05/10/2015). 
adversario reconocido en las empresas. El componente altamente disruptivo de estos repertorios, sumados a la reciente escalada urbana de la violencia política y a la radicalización de los discursos en el movimiento, hacen improbable que una continuidad en las mismas estrategias represivas del gobierno abra caminos de paz y diálogo. Si bien la supuesta "profesionalización militar" parece aún rudimentaria (y se requieren mayores antecedentes para caracterizarla), es posible prever que, de la mano del aumento de la represión, podría marcar también la pauta de la conflictividad y la violencia en el curso futuro de la contienda. Por su parte, la emergencia de diversas comunidades autónomas y organizaciones, como el Lof en Resistencia Tirúa-Lleu-Lleu (www.laizquierdadiario.cl, 15/11/2015), con proyectos de autonomía local y control productivo territorial, ciertamente hablan de una gran fragmentación del movimiento, pero sin duda revitalizan la capacidad disruptiva de este encarnada históricamente en la CAM, de gran influencia en Arauco (y por la Alianza Territorial de Malleco). Así también, la contienda ya no se remite hoy a La Araucanía y Arauco, sino que también se propaga por regiones del sur donde nuevos proyectos energético-extractivos amenazan al territorio mapuche, y los marcos y los repertorios de acción colectiva se radicalizan incluso entre las organizaciones más moderadas y dialogantes. Ciertamente, los marcos y los repertorios radicales ya no son monopolio de una organización en un ciclo de contienda que manifiesta una radicalización de la cultura movimentista.

Sin embargo, el gobierno no da señales claras de apertura al diálogo e incentivos a la vía institucional (salvo la pretensión del Ministerio del Interior de articular un amplio acuerdo jurídico-policial para resolver la "delincuencia" en territorio mapuche [La Tercera, 09/12/2015]). La Presidenta no visita la Región de La Araucanía, no cumple sus compromisos programáticos, reforma el sistema binominal sin medidas de inclusión para los pueblos originarios y no toma en consideración las propuestas de canalización institucional que surgen desde la propia clase política (Comisión Asesora Presidencial en Descentralización y Desarrollo Regional, 2014; www.politicaindígena.org, s/f), e incluso en julio de 2015 le da urgencia al proyecto de ley que prorroga el fomento forestal, sin previa consulta. Esta última medida, descartada incluso por Piñera, desató una gran actividad de protesta en la provincia de Arauco (El Mostrador, 23/07/2015). Solo la reciente investigación judicial acerca de la colusión del papel higiénico que involucra al grupo Matte -mencionada en la Introducción de este estudio- ha logrado quitarle urgencia a la prórroga del proyecto.

En la que sería la mayor crisis institucional de la postdictadura y con los índices de popularidad más bajos de las últimas décadas (La Tercera, 05/09/2015; El Mercurio, Economía y Negocios, 12/09/2015), el gobierno insiste hoy en dar una respuesta policial y economicista (asumiendo que el problema se trata meramente de delincuencia y pobreza) a un conflicto que el movimiento mapuche entiende como eminentemente político. Esta reacia disposición de las autoridades ciertamente desincentiva la moderación, legitima la confrontación y activa nuevos repertorios de acción colectiva. Si bien el movimiento se muestra fragmentado organizativamente en el último ciclo de contienda, las convicciones se fortalecen, las posturas se radicalizan entre los actores (incluido un gobierno que no dialoga) y la violencia se descontrola con nuevas víctimas. Los agricultores y camioneros de La Araucanía víctimas de la violencia, como también las víctimas mapuches de la violencia 
policial, parecen ser víctimas del desgobierno que impera en una zona donde los principales resguardos los reciben las empresas forestales (EI Werken, 24/04/2015), pero principalmente de la reticencia del gobierno a dar respuestas políticas. El último suspiro de las alternativas políticas parece haberse dado con la destitución del Intendente de La Araucanía, Francisco Huenchumilla, el mismo día que le presentaba al gobierno una propuesta con soluciones institucionales al conflicto.

Sin respuestas estructurales al conflicto, el gobierno despliega una estrategia errática de supresión de la protesta, que solo la perpetúa y radicaliza. Las iniciativas, por un lado, se remiten a una restitución territorial insuficiente y anclada en la ya histórica burocracia e ineficiencia de la CONADI y, por otro, a un aumento desmesurado del gasto policial en la zona, que fomenta el clima bélico y la represión indiscriminada. Mientras sobrevuelan la zona helicópteros y las tanquetas son parte del tráfico vehicular habitual (El Ciudadano, 06/02/2015), la protesta radical se incentiva en un contexto de nula inclusión política para las iniciativas moderadas.

Los datos recabados tanto en prensa como en las entrevistas desarrolladas entre comunidades de Arauco en conflicto dan cuenta del fortalecimiento y generalización de marcos y repertorios que antes se identificaban principalmente como propios de los sectores más radicalizados. Los resultados muestran una radicalización generalizada de la resistencia mapuche, con organizaciones moderadas que ahora contarían con diagnósticos del escenario significativamente similares a los históricos de la CAM y con modalidades de protesta altamente confrontacionales. Los estrechos márgenes disponibles para la vía institucional y la negativa evaluación de la industria forestal y de las respuestas gubernamentales por parte de las comunidades han legitimado una resistencia que combina el diálogo con la confrontación y la violencia política. Las interrogantes acerca del curso posterior de la protesta son profundas.

La principal preocupación es que la zona de conflicto tiende a asumir características de un régimen local escasamente democrático y con altos niveles de desgobierno e ineficiencia en la implementación de las políticas públicas. Este escenario, en términos de Tilly, se aproximaría a la tipología de régimen "no democrático con baja capacidad gubernamental", precisamente aquella relación entre Estado y sociedad que tiende a altos niveles de violencia, con márgenes para la arbitrariedad y el surgimiento de bandas o grupos armados.

El último ciclo de contienda se muestra como una meseta de niveles altos y generalizados de confrontación, de cierta acumulación de fuerzas y de acentuada alineación (más en repertorios y marcos cognitivos radicales que a nivel organizativo). No se descarta que frente a un cambio significativo del escenario esta tensa meseta pueda dar pie a un nuevo ciclo de contienda de inusitada violencia ${ }^{22}$. Sin embargo, la proyección de escenarios no resulta fácil frente a una contienda altamente dinámica como la estudiada.

22 La reciente exclusión de las comunidades con predios tomados en el beneficio de compra de la CONADI se vislumbra como un factor de gran tensión para el 2016, pues -más allá de las ineficiencias e irregularidad del 


\section{CONCLUSIONES}

Luego de la breve descripción histórica realizada de los diversos ciclos de la contienda política en territorio mapuche y de la identificación de nuevos marcos y repertorios de acción, es posible identificar particularidades que caracterizan el contexto actual y que seguramente marcarán el curso del conflicto. Sin duda, el escenario actual se caracteriza por el altisonante espectáculo policial, por un profundo descrédito institucional, por la legitimación de la violencia política y por la emergencia de una cultura movimentista radical, con marcos y repertorios radicales frente a la industria forestal. El contexto actual es distinto a los precedentes, y en particular ostensiblemente diferente a los ciclos previos al 2011. Sin embargo, no es posible identificar si la actual tensión en territorio mapuche corresponde a la resaca del peak de 2012 o si es el comienzo de una nueva escala de la actividad contenciosa.

Las señales dadas por el actual gobierno parecen minar los últimos vasos comunicantes entre el pueblo mapuche y el Estado chileno. La solución política demandada por gran parte del movimiento parece alejarse con la actual deslegitimidad institucional y la gestión de un gobierno que se rehúsa a reconocer las raíces estructurales e históricas del conflicto. Las medidas liberales de apoyo a la productividad, combinadas con una férrea militarización de la zona, no han hecho en estos años más que radicalizar las visiones y las acciones colectivas del movimiento. Después de 25 años de Nueva Imperial, el movimiento mapuche acumula no solo desencanto, sino también experiencia concreta sobre los límites actuales de la vía institucional y no hace más que afianzar sus convicciones y potenciar su capacidad disruptiva.

El incremento de la tensión, ciertamente, responde a la nula apertura política, con una escasa disposición al diálogo de parte del gobierno y del gran capital forestal (especialmente Mininco), sin embargo, también a la radicalización de los marcos interpretativos y de los repertorios de contienda del propio movimiento mapuche. La negativa evaluación del escenario actual y la radicalización de las modalidades de acción colectiva son propias de un movimiento que no ha dejado de construirse activamente en la interacción con el propio sistema político y sus adversarios. La radicalización de los discursos y repertorios, incluso entre los más moderados, responde -más que a modas- a la historia misma del conflicto y a la profundización de la cerrazón política en la relación Estado de Chile-Pueblo Mapuche. La transversalización de los "nuevos" marcos de la "deslegitimidad institucional", de la "legitimidad de la confrontación y de la violencia política", de la "oposición a la industria forestal" y de la "espiritualidad mapuche y el Buen Vivir", van de la mano de repertorios altamente disruptivos que comienzan a caracterizar la contienda en Arauco, la "reapropiación de la madera" y los ataques "incendiarios a la propiedad forestal" que incluso han escalado a zonas urbanas.

Sin lugar a dudas, los hallazgos de esta investigación fortalecen la idea del pueblo mapuche como un actor político que, en su faceta de movimiento, canaliza estratégicamente -con

Fondo de Tierras- ha representado un catalizador del conflicto y bien lo supo Piñera cuando el 2011 tuvo que reestablecerlo por la escalada de la protesta. 
más o menos certezas- sus objetivos colectivos en oposición a un adversario reconocido, concretamente la dupla gran capital forestal/Estado chileno. La imagen de un actor irascible e irracional no puede ser más lejana a la información recogida en esta investigación acerca del movimiento mapuche. La violencia es parte de un repertorio legitimado por el cierre de las vías políticas, pero difícilmente corresponde a una alternativa inmediata seleccionada antojadizamente. Incluso entre las posiciones más radicales, la violencia política se ha ido combinando estratégicamente con iniciativas institucionales y dialogantes. En última instancia, la radicalización actual de las interpretaciones de las acciones colectivas dificulta hablar de mapuches "pacíficos" y "violentos", de mapuches "buenos" y "malos".

Los embates represivos tanto policiales como judiciales han representado elevados costos humanos y organizativos para el movimiento, sin embargo, este no ha retrocedido en su labor estratégico-discursiva y en su capacidad disruptiva. Evidentemente, la capacidad organizativa y "estratégico-militar" de las organizaciones más rupturistas, como la CAM, se ha visto mermada, pero sus discursos son más vigentes y transversales que nunca. Aun cuando han sido perseguidos, criminalizados y estigmatizados, los actores más radicales han visto cómo sus repertorios y diagnósticos -más que sus propuestas- ya no les son exclusivas y se han generalizado al interior del movimiento mapuche. Sin duda, la profunda deslegitimidad de la vía institucional les ha dado la razón. Parece no ser necesario pensar en la liberación nacional mapuche para reconocer la necesidad de adoptar repertorios radicales. Y así lo manifiestan las propias comunidades entrevistadas que coinciden en el diagnóstico y en sus acciones, aun cuando asumen distintos proyectos para la autodeterminación, como la liberación nacional, la autonomía regional o la inclusión política con derechos especiales. El movimiento, ciertamente, se muestra más fragmentado organizativamente que en los ciclos de contienda previos, pero altamente sintonizado en sus repertorios y discursos. Los años transcurridos, la experiencia contenciosa acumulada, pero también -y principalmente- la cerrazón política, han gestado una "cultura contenciosa" radical en el movimiento mapuche.

Con objetivos políticos claros como la conquista de derechos colectivos y la recuperación territorial, y con repertorios que apuntan directamente al objeto de sus demandas y denuncias (la "propiedad" de las empresas forestales), el accionar del movimiento se distingue con claridad de manifestaciones terroristas o delincuenciales, representando más bien un movimiento político altamente disruptivo y dispuesto a asumir elevados costos en su accionar. En tal escenario, la tarea desmovilizadora del gobierno parece cuesta arriba si continúa negándose a responder a las demandas estructurales e institucionales del movimiento e insiste en reducir aún más los escasos espacios de diálogo e interacción político-institucional.

Por último, es importante sostener que si bien las predicciones resultan riesgosas en ciencias sociales, las marcadas tendencias que evidencia el escenario actual de la contienda seguramente aminoran la probabilidad de error. El escenario es crítico y una escalada de la violencia es altamente probable a corto o mediano plazo. Si bien gran parte de las conclusiones de este estudio se basan en hallazgos relativos principalmente a la provincia de Arauco (para futuros estudios se requiere un trabajo de campo con mayor cobertura territorial, incluyendo las regiones aledañas), el análisis sociohistórico desarrollado es de amplio alcance e identifica 
macrotendencias que exceden lo local y aportan importantes elementos de análisis de la dinámica relación del movimiento mapuche con el Estado chileno y el gran capital forestal. Ciertamente, la episódica violencia del ciclo actual podría exacerbarse dramáticamente en virtud de cambios coyunturales en el escenario político, como por ejemplo con un posible realineamiento de las coaliciones políticas, la llegada de un gobierno aún más represivo y de derecha (aportando nuevos aliados al interior de una oposición "progresista" y de una ciudadanía movilizada), con la implementación de algún megaproyecto que el movimiento reconozca como una amenaza para su supervivencia y el medioambiente (en Arauco ya existe preocupación por un proyecto minero de uranio y cadmio en la zona del lago Lleu-Lleu), con la posible (re)emergencia de grupos paramilitares (La Nación, 19/05/2015) o directamente a partir de un desenlace fatal que mediáticamente justifique una nueva ola represiva. En lo inmediato, el actual inicio de la temporada de cosecha forestal y el cierre para el 2016 del Fondo de Tierras para aquellas comunidades en procesos de recuperación territorial, en los hechos representan posibles detonantes de una escalada de la conflictividad. Ciertamente, en un escenario así de complejo, una escalada de la conflictividad supone el riesgo de que la violencia, en última instancia, vaya dejando de ser un efectivo recurso estratégico para la desmovilización (represión) y para la movilización (protesta) y se termine escapando del control tanto de las autoridades como de las propias comunidades.

Por lo pronto, el movimiento conjuga la vía institucional con repertorios violentos de autodefensa como también de "ataques dispersos" que mantienen vigente su capacidad disruptiva. Frente a un movimiento que radicaliza sus posiciones y acciones, el gobierno necesita revisar su proyecto desmovilizador, pues ciertamente ha tenido efectos contraproducentes. Los últimos 25 años han demostrado que no es la represión, el miedo y el aumento del costo de la protesta lo que resolverá el conflicto. La única respuesta que los gobiernos aún no prueban es la apertura democrática de los canales políticos para el pueblo mapuche. Desde diversas posiciones del movimiento mapuche se escucha que esta sería una vía que reduciría significativamente los costos humanos y sociales del conflicto. Hasta ahora, sin duda, no existe real incentivo para el abandono de los repertorios de contienda más radicales.

\section{BIBLIOGRAFÍA}

Aburto Panguilef, M. (2009): La violencia colonial en Wallmapu, disponible en http://www.mapuchenation.org/espanol/html/documentos/doc-90.htm (recuperado el 20/05/2015).

Amolef, F. (2005): "La alteridad en el discurso mediático: los mapuche y la prensa chilena", Boletín IFP, 2 (6), disponible en http://www.portalcomunicacion.com/dialeg/paper/pdf/202_amolef. pdf (recuperado el 27/04/2014).

Anaya, J. (2009): La situación de los pueblos indígenas en Chile: seguimiento a las recomendaciones hechas por el Relator Especial anterior, Informe del Relator Especial sobre la Situación de los Derechos Humanos y las Libertades Fundamentales de los Indígenas, Consejo de Derechos Humanos.

Aylwin, J., R. Sánchez y N. Yáñez (2014): Pueblo mapuche y recursos forestales en Chile: devastación y conservación en un contexto de globalización económica, Observatorio Ciudadano y Grupo Internacional de Trabajo sobre Pueblos Indígenas (IWGIA), Santiago de Chile. 
Bascopé, J. (2005): ¿Representantes o líderes? Organización política y conflicto entre los lafkenche del ADI Lleu-Lleu, VIII Región, Tesis para optar al título de Antropólogo Social, Facultad de Ciencias Sociales, Universidad de Chile, Santiago.

Bengoa, J. (1985): Historia del pueblo mapuche, siglos XIX y XX, Ediciones SUR, Santiago de Chile.

(1999): Historia de un conflicto: El Estado y los mapuche en el siglo XX, Planeta, Santiago de Chile.

(2007): La emergencia indígena en América Latina, Fondo de Cultura Económica, Santiago de Chile.

Brockett, C. (1991): "The structure of political opportunities and peasant mobilization in Central America", Comparative Politics, 23 (3), pp. 253-274.

Brysk, A. (2009): De la tribu a la aldea global. Derechos de los pueblos indígenas, redes transnacionales y relaciones internacionales en América Latina, Ediciones Bellaterra, Barcelona.

Caniuqueo, S., R. Levil, P. Marimán y J. Millalén (2006): i ...Escucha, winka... ! Cuatro ensayos de Historia Nacional Mapuche y un epílogo sobre el futuro, LOM, Santiago de Chile.

Carruthers, D. y P. Rodríguez (2008): “Testing democracy's promise: indigenous mobilization and the Chilean State", European Review of Latin American and Caribbean Studies, 85, pp. 3-21.

Cayuqueo, P. (2006): Participación y voto mapuche en las Municipales, disponible en http://www. mapunet.org/documentos/mapuches/mapuches_municipales.pdf (recuperado el 23/10/2015).

Comisión Asesora Presidencial en Descentralización y Desarrollo Regional (2014): Propuesta de política de Estado y agenda para la descentralización y el desarrollo territorial de Chile.

Comisión Ética Contra la Tortura (2011): Informe de Derechos Humanos, Quimantú, Santiago de Chile. (2012): Informe de Derechos Humanos, Quimantú, Santiago de Chile.

Correa, M. y E. Mella (2010): Las razones del Illkun/Enojo: memoria, despojo y criminalización en el territorio mapuche de Malleco, LOM, Santiago de Chile.

Correa, M., R. Molina y N. Yáñez (2005): La reforma agraria y las tierras mapuche 1962-1975, LOM, Santiago de Chile.

Della Porta, D. (1999): "Movimientos sociales y Estado: algunas ideas en torno a la represión policial de la protesta", en D. McAdam, J. McCarthy y Z. Mayer: Movimientos sociales: perspectivas comparadas, Istmo, Madrid, pp. 100-142.

Donoso, J. (2011): Violencia política en el sur de Chile: la Alianza Territorial Mapuche Pü Löf Xawün y el Estado chileno en el gobierno de Michelle Bachelet, Tesis doctoral, Doctorado de Investigación en Ciencias Sociales, FLACSO México.

Echeverría, C., D. Coomes, J. Salas, J. Rey-Benayas, A. Lara y A. Newton (2006): “Rapid deforestation and fragmentation of Chilean temperate forests", Biological Conservation, 130 (4), pp. 481-494.

Emmerson, B. (2014): Report of the Special Rapporteur on the promotion and protection of human rights and fundamental freedoms while countering terrorism, Human Rights Council.

Foerster, R. (1999): "Movimiento étnico o movimiento etno-nacional mapuche", Revista de Crítica Cultural, 18, pp. 52-58.

(2004): ¿Pactos de sumisión o actos de rebelión? Una aproximación histórica y antropológica a los mapuches de la costa de Arauco, Chile, Tesis doctoral, Universidad de Leiden, Holanda. 
Foerster, R. y S. Montecino (1988): Organizaciones, líderes y contiendas mapuches (1900-1970), Ediciones CEM, Santiago de Chile.

Gamson, W. (1975): The strategy of social protest, Dorsey Press, Homewood, II.

(1992): "The psychology of the collective action", en A. Morris y C. Mueller (eds.): Frontiers of the social movement theory, Yale University Press, New Haven.

González Calleja, E. (2002): La violencia en la política: perspectivas teóricas sobre el empleo deliberado de la fuerza en los conflictos de poder, Consejo Superior de Investigaciones Científicas (CSIC), Madrid.

González-Hidalgo, M. (2015): ¿Agua para quién? Escasez hídrica y plantaciones forestales en la Provincia de Arauco, en colaboración con iniciativa "Agua que has de beber" y ONG Forestales por el Bosque Nativo.

Gupta, D. (2002): Radical flank effects: the effect of radical-moderate splits in regional nationalist movements, Paper presentado en Conference of Europeanists, 14-16 de marzo, Chicago, EE.UU.

Gurr, T. (1970): Why men rebel?, Princeton University Press, Princeton.

Haines, H. (1997): Black radicalization and the funding of civil rights: 1957-1970, en D. McAdam y D. Snow (eds.): Social movements: readings on their emergence, mobilization and dynamics, Roxbury, Los Angeles, pp. 440-441.

Hernández, C. (2014): "A veinte años de la Ley Indígena: tiempo de diagnóstico", Serie Informe Sociedad y Política, 140.

Huenchumilla, F. (2015): Propuesta al gobierno respecto de la situación de la Región de La Araucanía, disponible en www.politicaindigena.org/pdf/Propuesta-Huenchumilla.pdf (recuperado el 19/11/2015).

Ibarra, P. (2000): "Los estudios sobre los movimientos sociales: estado de la cuestión", Revista Española de Ciencia Política, 1 (2), pp. 271-290.

Instituto Nacional de Derechos Humanos [INDH] (2015): Informe Anual 2014. Situación de los Derechos Humanos en Chile, Instituto Nacional de Derechos Humanos, Santiago de Chile.

(2014): Estudio exploratorio Estado de Chile y Pueblo Mapuche: análisis de tendencias en materia de violencia estatal en la Región de La Araucanía, Instituto Nacional de Derechos Humanos, Santiago de Chile.

Jenkins, J.C. y C.M. Eckert (1986): “Channeling black insurgency: elite patronage and professional social movement organizations in the development of the black movement", American Sociological Review, 51 (6), pp. 812-829.

Kriesi, H. et al. (1998): New social movements in Western Europe. A comparative analysis, University of Minnesota Press, Minneapolis.

Labrín, J.M. (2011): Análisis de cobertura y tratamiento de conflictos indígenas 2010-2011, Universidad de Chile/Unesco, Santiago de Chile.

Le Bon, G. (2004): Psicología de las masas. Estudio sobre la psicología de las multitudes, La Editorial Virtual, Buenos Aires.

Le Bonniec, F. (2002): "Las identidades territoriales o cómo hacer historia hoy día", en R. Morales (comp.): Territorialidad Mapuche en el Siglo XX, Instituto de Estudios Indígenas-UFRO/Escaparate Ediciones, Concepción. 
López, S. y L. Nitrihual (2014): Vidas de papel. Negocio de la madera y conflicto intercultural en Chile, Universidad de La Frontera, Temuco.

Marimán, P. F. (1990): "Algunas consideraciones en torno al voto mapuche", Revista Liwen, 2, pp. 25-32.

(2012): Autodeterminación. Ideas políticas mapuche en el albor del siglo XXI, LOM, Santiago de Chile.

Martínez, C. (1995): "Comunidades y territorios Lafkenche, los mapuches de Rancura al Moncul", Serie de Investigación, Instituto de Estudios Indígenas, Temuco.

McAdam, D. (1982): Political process and the development of black insurgency 1930-1970, University of Chicago Press, Chicago.

(1999): "Orígenes terminológicos, problemas actuales y futuras líneas de investigación", en D. McAdam, J. McCarthy y M. Zald: Movimientos sociales: perspectivas comparadas, Istmo, Madrid, pp. 49-70.

McAdam, D., J. McCarthy y M. Zald (1999): Movimientos sociales: perspectivas comparadas, Istmo, Madrid.

McAdam, D. y S. Tarrow (2010): "Ballots and barricades: on the reciprocal relationship between elections and social movements", Perspectives on Politics, 8 (2), pp. 529-542.

(2011): "Introduction. Dynamics of contention ten years on", Mobilization: An International Journal, 16 (1), pp. 1-10.

McAdam, D., S. Tarrow y C. Tilly (1996): "To map Contentious Politics", Mobilization: An International Journal, I (1), pp. 17-34.

(2001): Dynamics of Contention, Cambridge University Press, Cambridge.

(2005): Dinámica de la contienda política, Hacer, Barcelona.

(2008): "Methods for measuring mechanisms of contention", Qualitative Sociology, 31 (4), pp. 307-331.

(2009): "Comparative perspectives on Contentious Politics", en M. Lichbach y A. Zuckerman (eds.): Comparative politics: rationality, culture, and structure, Cambridge University Press, Nueva York.

McCarthy, J. y M. Zald (1977): "Resource mobilization and social movements: a partial theory", American Journal of Sociology, 82, pp. 1212-1241.

Mella, E. (2007): Los mapuches ante la justicia, LOM, Santiago de Chile.

Multigremial de la Araucanía (2012-2015): Barómetro de conflicto, disponible en www. multigremialaraucania.cl/es_barometro_de_conflicto.php (recuperado el 05/12/2015).

Neveu, E. (2000): Sociología de los movimientos sociales (segunda edición corregida y aumentada). Abya-Yala, Quito.

Olson, M. (1992): "La lógica de la acción colectiva”, en A. Batlle i Rubio (coord.): Diez textos básicos de ciencia política, Ariel, Barcelona, pp. 203-220.

Pairicán, F. (2014): Malón. La rebelión del movimiento mapuche 1990-2013, Pehuén, Santiago de Chile.

Programa de Naciones Unidas para el Desarrollo [PNUD] (2008): Desarrollo Humano en Chile Rural. 6 Millones por Nuevos Caminos, Programa de Naciones Unidas para el Desarrollo, Santiago de Chile. 
Rojas Pedemonte, N. (2013): Movilización y desmovilización. Zapatismo y sindicalismo en el México de Salinas de Gortari, Tesis Doctoral, Programa de Doctorado en Sociología de la Universidad de Barcelona, España.

Rucht, D. (1999): "El impacto de los contextos nacionales sobre la estructura de los movimientos sociales: un estudio comparado transnacional y entre movimientos", en D. McAdam, J. McCarthy y M. Zald (eds.) (1999): Movimientos sociales: perspectivas comparadas, Istmo, Madrid.

Rucht, D. y S. Bödecker (2001): "Catch the waves: How to identify and analyse protest waves", artículo presentado en Taller "Politics, power and movements. Workshop celebration honoring Sidney Tarrow", Cornell University, Ithaca, New York, 3-4 de junio.

Salazar, G. (2006): La violencia política popular en las "Grandes Alamedas", LOM, Santiago de Chile.

Seguel, A. (2006): Crónicas de desencuentros: Gobierno de Ricardo Lagos versus movimiento social mapuche, disponible en www.mapuexpress.net/content/publications/print.php?id=282 (recuperado el 01/03/2015).

Smelser, N. (1962): Theory of collective behavior, Free Press, New York.

Stavenhagen, R. (2003): Derechos humanos y cuestiones indígenas, Informe del Relator Especial sobre la situación de los derechos humanos y las libertades fundamentales de los indígenas, disponible en http://www.acnur.org/t3/fileadmin/Documentos/BDL/2006/4353.pdf?view=1 (recuperado el 01/03/2014).

Tarrow, S. (1967): Peasant communism in Southern Italy, Yale University Press, New Haven.

(1977): Between center and periphery: grassroots politicians in Italy and France, Yale University Press, New Heaven.

(1989): Democracy and disorder: protest and politics in Italy 1965-1975, Clarendon, Oxford.

(1997): El poder en movimiento, primera edición, Alianza, Madrid.

(2005): The new transnational activism, Cambridge University Press, Cambridge.

(2009): El poder en movimiento, segunda edición, Alianza, Madrid.

(2010): "The strategy of paired comparison: toward a Theory of Practice", Comparative Political Studies, 43, pp. 230-259.

(2011): Power in movement, Cambridge University Press, New York.

(2012): Strangers at the gates. Movements and States in Contentious Politics, Cambridge University Press, New York.

Tarrow, S. y C. Tilly (2007): Contentious Politics, Paradigm Publishers, Boulder.

Tilly, C. (1978): From mobilization to revolution, Random House, New York.

(1991): Grandes estructuras, procesos amplios, comparaciones enormes, Alianza, Madrid. (2003): Politics of collective violence, Cambridge University Press, Cambridge.

(2006): Regimes and repertoires, University of Chicago Press, Chicago.

(2007): Violencia colectiva, Hacer, Barcelona.

(2007): Democracy, Cambridge University Press, Nueva York. 
Toledo Llancaleo, V. (2007a): "La memoria de las tierras antiguas tocando a las puertas del derecho. Políticas de la memoria mapuche en la transición chilena", Revista de Historia Social y de las Mentalidades, XI (I), pp.67-85.

(2007b): “Prima Ratio. Movilización mapuche y política penal. Los marcos de la política indígena en Chile 1990-2007", OSAL, VIII (22), pp. 253-275.

(2001): “Esto también va haciendo autonomía. La estrategia territorial de las comunidades Lafkenches de Tirúa", en Espacios locales y desarrollo de la ciudadanía, Centro de Análisis de Políticas Públicas, Universidad de Chile, Santiago.

Tricot, T. (2009): "Lumako: punto de inflexión en el desarrollo del nuevo movimiento mapuche", HAOL, 19, pp. 77-96.

Universidad Diego Portales (2013): Informe anual sobre Derechos Humanos en Chile, Universidad Diego Portales, Santiago de Chile.

Vergara, J.I., H. Gundermann y R. Foerster (2013): Estado, conflicto étnico y cultura: estudios sobre pueblos indígenas en Chile, Universidad Católica del Norte, Santiago de Chile.

Von Stein, L. (1981): Movimientos sociales y monarquía, Centro de Estudios Constitucionales, Madrid.

Yashar, D. (2005): Contesting citizenship in Latin America. The Rise of indigenous movements and the postliberal challenge, Cambridge University Press, New York.

\section{Artículos de prensa y páginas web consultadas:}

"27 de agosto: una larga jornada de polarización política, social y enfrentamientos" (28/08/2015), www.rebelión.org.

"4 camiones quemados y un conductor herido en nuevo ataque en la Araucanía" (26/9/2015), www. portalmalleco.cl.

"A 13 llega el número de carabineros heridos en choques con mapuches en la provincia de Arauco" (05/10/2014), El Mostrador.

"Aleuy: Atentados en Arauco no tienen relación con causa mapuche, sino al robo de maderas" (15/12/2014), www.emol.com.

"Araucanía: grupo nacionalista anuncia autodefensa armada frente a ataques" (19/05/2015), La Nación.

"Asamblea analizó los graves hechos ocurridos recientemente en Tirúa" (05/10/2015), estacióninfo. blogspot.com.

"Bajo apoyo a Presidenta Bachelet (22\%) marca récord en encuesta CEP" (12/09/2015), El Mercurio, Economía y Negocios.

“Biobío: advierten sobre mayor poder de fuego en reacción a arrestos por robo de madera" (23/10/2015), El Mercurio, Economía y Negocios.

"Bloqueos, barricadas y emboscada policial en ruta Tirúa-Cañete: Dos carabineros heridos" (20/11/2013), La Segunda.

"Burgos se querella por ley de seguridad interior por quema de camiones en la Araucanía" (9/12/2015), El Mercurio.

"Camioneros inician viaje en caravana con máquinas quemadas a Santiago" (24/08/2015), El Mercurio.

"Colusión papelera, desfalco forestal y despojo territorial" (12/11/2015), El Mostrador. 
"Continúan acciones de resistencia mapuche en diferentes territorios del Wallmapu" (30/12/2014), www.werken.cl.

"Comunicado de José Huenuche" (24/01/2015), www.mapuexpress.org.

"Comunicado público de lof en resistencia Tirúa Lleu-Lleu" (15/11/2015), www.laizquierdadiario.cl.

"Descarnado análisis jesuita. 'En Tirúa la verdad es otra'" (02/11/2008), Diario del Sur.

“D.L. 701 en trámite: la radicalización del conflicto forestal” (23/07/2015), El Mostrador.

"Dos atentados se registran en menos de 24 horas en Arauco" (11/10/2015), La Tercera.

"Dos casetas y una camioneta fueron quemadas en medio de un apagón en Tirúa" (24/9/2015), www. soychile.cl.

"Editorial: Robo de madera en La Araucanía" (22/10/2015), La Tercera.

"El enviado especial" (30/07/2015), Qué Pasa.

"Eliodoro Matte visita la moneda para reunirse con jefa de gabinete de presidenta Bachelet" (21/07/2015), www.biobiochile.cl.

"Emboscada a piquete policial deja tres carabineros heridos en Cañete" (24/10/2014), El Mostrador.

"Encapuchados balean a un menor de 14 años en Tirúa" (18/11/2015), www.biobiochile.cl.

"Encapuchados queman maquinarias en predio de empresa Mininco" (11/9/2015), www.biobiochile.cl.

"En dos meses van 35 acusados de robar madera en provincia de Arauco" (19/02/2015), El Mercurio.

"Enfrentamientos en Arauco dejan a 13 carabineros lesionados" (05/10/2014), La Tercera.

"Enfrentamiento en predio forestal en Tirúa deja siete carabineros heridos" (04/03/2014), El Mercurio.

"Escándalo en Chile por supuesto nexo entre las Farc y grupos mapuches" (15/09/2008), El Tiempo.

"Fiscalía suma 97 causas y 61 imputados por robo de madera" (13/11/2015), El Sur.

"Gobierno en tela de juicio por muerte de comunero mapuche" (02/11/2015), Portal Radio Universidad de Chile.

"Gobierno: Ataque a helicóptero de Carabineros no tiene relación con la causa mapuche" (28/12/2014), www.cooperativa.cl.

"Hallan culpables de 'autoatentado' a transportistas en La Araucanía" (02/07/2015), El Mercurio.

"Informe de derechos humanos para el pueblo mapuche" (30/06/2013), www.mapuche-nation.org.

"Interior fija reunión clave que busca sellar acuerdo político en La Araucanía" (09/12/2015), La Tercera.

"Investigan incendio que destruyó casetas y un vehículo en Tirúa" (24/9/2015), El Mercurio.

"José Huenuche: Habla desde la Cárcel de Lebu y aclara el 'Robo de Madera'" (s/f), www.mapuexpress.org.

"La cara actual de la guerra sucia y la injusticia en Chile" (14/01/2014), Movimiento Generación 80.

"La lista completa: la verdad sobre las 1.123 empresas que financian la política en Chile" (23/4/2015), www.ciperchile.cl.

"La política de Bush en territorio mapuche" (06/02/2015), El Ciudadano.

"La verdad de la represión en el fundo El Canelo (Tirúa)" (05/03/2014), www.mapuexpress.org.

"Llaitul depone la huelga de hambre" (31/12/2007), Meli Wixan Mapu. 
"Líderes mapuches y expertos critican anuncios de Piñera en materia indígena" (05/06/2010), Metiendo Ruido.

"Los poderosos vehículos blindados que entregó Burgos a Carabineros de La Araucanía" (26/11/2015), www.biobiochile.cl.

"Manifestantes bloquearon ruta que une Cañete y Tirúa en el sector de Puente Negro" (24/9/2014), www.soychile.cl.

“Movilizaciones en Cañete y Tirúa ponen en alerta a forestales y autoridades chilenas" (18/12/2013), País Mapuche.

"Nuevo ataque incendiario afecta a dos camiones en Cañete" (10/10/2015), La Tercera.

"Otra vez asoma el montaje FARC-mapuche" (08/08/2015), El Desconcierto.

"Parlamento aprueba glosa en presupuesto de Conadi que impide compra de tierras tomadas" (27/11/2015), www.sofofa.cl.

"Parlamento aprueba glosa en presupuesto de Conadi que impide compra de tierras tomadas" (27/11/2015), El Mercurio.

"Presidente Piñera: Los incendios intencionales son delitos terroristas" (09/01/2012), www.cooperativa.cl.

"Propuesta de acuerdo por la paz social en la Araucanía" (s/f), www.politicaindigena.org.

"Queman maquinarias de Forestal Mininco en Tirúa" (24/2015), El Mercurio, Economía y Negocios.

"Recursos millonarios destinados a defender las forestales y reprimir la resistencia Mapuche" (24/04/2015), www.werken.cl.

"Se busca: ¿Dónde se fue el 62\% de Bachelet" (05/09/2015), La Tercera.

“Transportistas son declarados culpables de 'autoatentado' en la Araucanía” (02/07/2015), El Mostrador.

"Vilcún: Atentado incendiario destruyó lechería en fundo Palermo de familia Luchsinger" (20/11/2015), www.biobiochile.cl.

"Wallmapu: Resistencia Mapuche" (11/09/2015), Red Latina Sin Fronteras. 